\title{
MODULAÇÃO DA MICROBIOTA INTESTINAL NA DOENÇA DE CROHN
}

\section{ARTIGO DE REVISÃO}

CARDOSO, Ariane da Silveira Messôr Araújo ${ }^{1}$

CARDOSO, Ariane da Silveira Messôr Araújo. Modulação da microbiota intestinal na doença de Crohn. Revista Científica Multidisciplinar Núcleo do Conhecimento. Ano 06, Ed. 04, Vol. 04, pp. 96-133. Abril. ISSN: 2448-0959, Link de acesso: https://www.nucleodoconhecimento.com.br/saude/modulacao-da-microbiota, DOI: 10.32749/nucleodoconhecimento.com.br/saude/modulacao-da-microbiota

\section{RESUMO}

Este trabalho buscou mostrar como promover a modulação da microbiota intestinal através da dieta e da suplementação de butirato, probióticos e prebióticos podem influenciar na evolução da Doença de Crohn (DC) e auxiliar na promoção de uma remissão sustentada. Dada a complexidade da doença e a disbiose promovida por esta e acentuada pelo tratamento verificou-se a necessidade de realizar um estudo aprofundado para avaliar como a dieta e a suplementação podem atuar de forma positiva, reduzindo a inflamação e a disbiose do portador de DC, promovendo e prolongando o tempo de remissão. Trata-se de uma revisão de literatura, de caráter qualitativo, de artigos publicados nos últimos 15 anos e livros publicados nos últimos 20 anos sobre modulação da microbiota através da dieta e dos suplementos supracitados em portadores de DC. Através desta revisão foi possível verificar que tanto a suplementação quanto dieta são capazes de interferir na composição da microbiota e na síntese de metabólitos das bactérias, como ácidos graxos de cadeia curta (AGCC), reduzindo a inflamação e promovendo a remissão clínica, porém por

\footnotetext{
${ }^{1}$ Bacharel em Nutrição. Pós-graduanda em Nutrigenômica e Modulação Intestinal.
}

RC: 82101

Disponível em: https://www.nucleodoconhecimento.com.br/saude/modulacao-damicrobiota 
caminhos distintos. Enquanto a suplementação de prebióticos e probióticos tenta reduzir a inflamação através da redução da disbiose, a dieta promove redução da inflamação e dos sintomas através da redução do estresse oxidativo, porém deixando a microbiota ainda mais disbiótica, mostrando que há dois caminhos para a redução do processo inflamatório e controle da doença. Por outro lado, a suplementação de butirato parece não influir diretamente na composição da microbiota, mas age como anti-inflamatório e melhora a saúde da barreira epitelial e reduz a translocação bacteriana, devido sua absorção e ação direta nas células $\mathrm{T}$ e nos colonócitos. Diante de tudo isso, concluímos que essas vias são complementares e, se utilizadas como um adjuvante ao tratamento farmacológico, podem conduzir a remissão mais rapidamente e favorecer com que esta seja sustentada por períodos mais longos. Apesar disso, reforço a necessidade de que se façam estudos em humanos, portadores de DC, a fim de avaliar a eficácia da combinação da dieta com suplementação de butirato, probiótico e prebiótico.

Palavras-chave: Doença de Crohn, Dieta, Butirato, Probiótico, Prebiótico.

\section{INTRODUÇÃO}

As doenças inflamatórias intestinais (DII) ocorrem em todo o mundo, porém tem maior incidência e países industrializados do que em países em desenvolvimento. Afeta principalmente pessoas em idade economicamente produtiva, sendo, portanto, de interesse de saúde pública. (ALEKSANDROVA; ROMERO-MOSQUERA; HERNANDEZ, 2017; HALFELD, 2015)

A Doença de Crohn é um tipo de DII, um tipo de distúrbio que cursa com inflamação crônica, cujo desenvolvimento está associado a uma predisposição genética, fatores ambientais como a dieta e a perda da tolerância da microbiota desregulada pelo sistema imunológico do portador. (ALEKSANDROVA; ROMERO-MOSQUERA; HERNANDEZ, 2017; YAN; LI, 2020)

RC: 82101

Disponível em: https://www.nucleodoconhecimento.com.br/saude/modulacao-damicrobiota 
A microbiota tem função de imunomoduladora, auxilia na nutrição e metabolismo, função de proteção, auxilia na manutenção da estrutura e funcionamento do TGI. Ela interage com o hospedeiro de forma simbiótica, e é capaz de interferir no seu estado de saúde ou doença. (MOREIRA; BARRA, 2015; MACHADO et al., 2015) A microbiota intestinal na DII tem como característica uma redução da sua diversidade, há um aumento de bactérias pró-inflamatórias, como Eisherichia e Fusobacterium, e uma redução das cepas anti-inflamatórias, como Faecalibacterium e Roseburia. (ALEKSANDROVA; ROMERO-MOSQUERA; HERNANDEZ, 2017) Cepas produtoras de ácidos graxos de cadeia curta (AGCC), principalmente o butirato, também são relatadas como diminuídas. (LASERNA-MENDIETA et al., 2018) A disbiose, essa variação na diversidade e na quantidade de bactérias da microbiota, é apontada como uma causa para o desenvolvimento da DII. (SOUZA, 2015)

O butirato é o AGCC mais presente no intestino e tem sido apontado como uma peça importante na regulação da imunidade, devido sua participação na maturação de linfócitos $T$ reguladores (Treg), promovendo a homeostase, na inibição da resposta inflamatória, além de fornecer energia para células intestinais e participar da manutenção da barreira, podendo ser uma alternativa para reduzir sintomas e inflamação no tratamento da DII. (SITKIN; VAKHITOV; POKROTNIEKS, 2018; LASERNA-MENDIETA et al., 2018)

Uma alternativa de tratamento da DIl pode ser a suplementação de probióticos, de cepas produtoras de butirato, e as principais cepas indicadas para esse fim são Faecalibacterium prausnitzii, Butyricicoccus pullicaecorum e Roseburia spp e restaurar a homeostase intestinal. (VAN IMMERSEEL F et al., 2010)

A dieta tem um papel importante no desenvolvimento da DII e tem sido utilizada como uma ferramenta no tratamento da doença, porém necessita de mais estudos quanto a sua implicação sobre a disbiose da microbiota e sua participação no desenvolvimento da inflamação. As alterações na dieta influenciam tanto no metabolismo da microbiota quanto no metabolismo do hospedeiro.

RC: 82101

Disponível em: https://www.nucleodoconhecimento.com.br/saude/modulacao-da- 
(ALEKSANDROVA; ROMERO-MOSQUERA; HERNANDEZ, 2017; PAIVA; MANTOVANI, 2015).

\section{OBJETIVOS}

\subsection{OBJETIVO GERAL}

O objetivo geral desse trabalho é descrever a influência da modulação da microbiota intestinal sobre o processo inflamatório na Doença de Crohn.

\subsection{OBJETIVOS ESPECÍFICOS}

- Explicar o que é microbiota, como ela pode influenciar no funcionamento do organismo e o que pode influenciar na composição dela;

- Conceituar o que é disbiose e identificar quais as possíveis alterações que podem ocorrer na composição da microbiota de um paciente com DC;

- Apresentar o efeito da dieta na modulação da microbiota intestinal em portadores de DII;

- Descrever o efeito da suplementação de butirato, probióticos e prebióticos em portadores de DII.

\section{METODOLOGIA}

O presente estudo é uma revisão de literatura, de caráter qualitativo, onde teve por finalidade realizar uma revisão de literatura sobre a modulação da microbiota intestinal através da dieta e do uso de suplementos de butirato, de probióticos e prebióticos na Doença de Crohn e a influência sobre o processo inflamatório.

Para um melhor tratamento dos objetivos convencionou-se desenvolver a pesquisa com base em livros sobre Doença Inflamatória Intestinal (DII) e microbiota intestinal publicados nos últimos 20 anos e artigos científicos do Pubmed e Scielo publicados

RC: 82101

Disponível em: https://www.nucleodoconhecimento.com.br/saude/modulacao-da$\underline{\text { microbiota }}$ 
nos últimos 15 anos, portanto, essa pesquisa está classificada como descritiva e exploratória. A busca foi feita no período de março de 2019 a maio de 2020. Foram selecionados artigos com o seguinte filtro: "Free full text", data de publicação "10 anos", tipos "Randomized Controlled Trial", "Meta-Analysis" e "Systematic Reviews". Os termos pesquisados foram: "Crohn's Disease", "Diet inflammation IBD", "microbiome Crohn's Disease”, "Butyrate Crohn's Disease”, "Probiotic Crohn's Disease", "Inulin Crohn's Disease", "Inulin IBD”.

Os procedimentos escolhidos foram o bibliográfico, pois serão utilizados livros e artigos científicos como fonte de pesquisa.

\section{REVISÃO DE LITERATURA}

\subsection{A DOENÇA DE CROHN}

Segundo relato do Dr. Korelitz (2014), em seu artigo para a Associação Brasileira de Colite Ulcerativa e Doença de Crohn, as primeiras pesquisas que deram origem ao que hoje chamamos de Doença de Crohn aconteceram em 1923, pelo Dr. Eli Moschcowitz, médico patologista, também no Hospital Mont Sinai, que pesquisava casos de granuloma inespecífico no intestino delgado em cadáveres.

A Doença de Crohn foi descrita com esse nome pela primeira vez em 1932, em homenagem a um dos médicos que se dedicaram a pesquisa dela: Dr. Burrill Bernard Crohn. Anteriormente chamada de lleíte terminal, devido a localização do desenvolvimento da doença ser na porção terminal do íleo, e, posteriormente, lleíte Regional, pois o termo "terminal" como parte do nome da doença sugeria que todo paciente iria a óbito por ela. A sugestão de colocar o nome de um dos médicos pesquisadores na doença deve-se ao fato do Dr. Crohn ser o responsável pela apresentação das pesquisas realizada em conjunto com outros médicos do Hospital Mont Sinai, em Nova lorque, e pelo seu nome sempre vir primeiro nos documentos em ordem alfabética. Dentre os médicos envolvidos nessas pesquisas iniciais estão

RC: 82101

Disponível em: https://www.nucleodoconhecimento.com.br/saude/modulacao-damicrobiota 
Dr. A. A. Berg, seu assistente e professor de clínica cirúrgica Leon Ginzburg, seu colega e cirurgião consultor Dr. Gordon David Oppenheimer (KORELITZ, 2014; CAMPOS; KOTZE, 2013).

Segundo Machado at. al. (2015), as DIl são distúrbios inflamatórios crônicos do intestino que se caracterizam por ativação inadequada da imunidade da mucosa intestinal, cujo estímulo é advindo também do conteúdo da microbiota intestinal, em indivíduos geneticamente suscetíveis. Valente at. al. (2015), definem a DC como um distúrbio inflamatório multifatorial, que afeta 0 tubo digestório e acomete, principalmente, pontos mais específicos como a região do íleo terminal, partes do cólon e ânus. Miszputen; Cury (2015), acrescentam que, apesar da DC ser classificada como DII, em função da sua localização, pode ocorrer em qualquer segmento do canal alimentar, da boca ao ânus, e, geralmente mais de uma área é afetada.

$\mathrm{Na}$ inflamação da DC se observa regiões saudáveis se intercalando com áreas acometidas pela doença, nas quais há alterações histológicas evidentes, formação de granulomas, infiltrado inflamatório e espessamento de submucosa, lesões iniciais podem se estender para áreas sadias, os sintomas variam de acordo com a apresentação, local afetado e extensão da inflamação, e ressecções cirúrgicas não evitam sua recorrência. Nesse sentido, fica claro a gravidade e os danos causados à medida que a inflamação aumenta (VALENTE et al., 2015; MISZPUTEN; CURY, 2015).

Miszputen; Cury (2015, p.24), descrevem nesse trecho as alterações morfológicas geradas pelo processo inflamatório:

As úlceras profundas que se formam em decorrência da inflamação, verdadeiras fissuras, chegam a criar trajetos fistulosos, comunicando o intestino ou o cólon com outras vísceras e estruturas vizinhas, ou terminam no meio exterior, mais frequentemente na região perianal e na parede abdominal, causando abscessos, intracavitários ou superficiais, que muitas vezes acompanham a complicação. Quando

RC: 82101

Disponível em: https://www.nucleodoconhecimento.com.br/saude/modulacao-da- 
as úlceras cicatrizam, geram deformidades, que podem levar a variados graus de estenoses do segmento doente.

Independente da região acometida pela doença, a DC pode assumir três formas distintas, seja como manifestação clínica inicial ou como evolução da doença: a inflamatória, cursando com febre, cólica, diarreia e emagrecimento; a estenosante, que é secundária ao edema, ao espasmo e à fibrose que se se instalam nas regiões lesionadas do intestino e causam sintomas como náusea, vômito, cólica e distensão com hipertimpanismo abdominal; e a fistulizante, que pode ser sintomática ou assintomática e é consequência do processo inflamatório do tipo transmural - que atinge todas as camadas da parede, da mucosa a serosa -, e penetrante (SILVA; LAUDANNA, 2007).

Figura 1- Representação esquemática dos tipos de DC: Inflamatória, Fistulisante e Estenosante

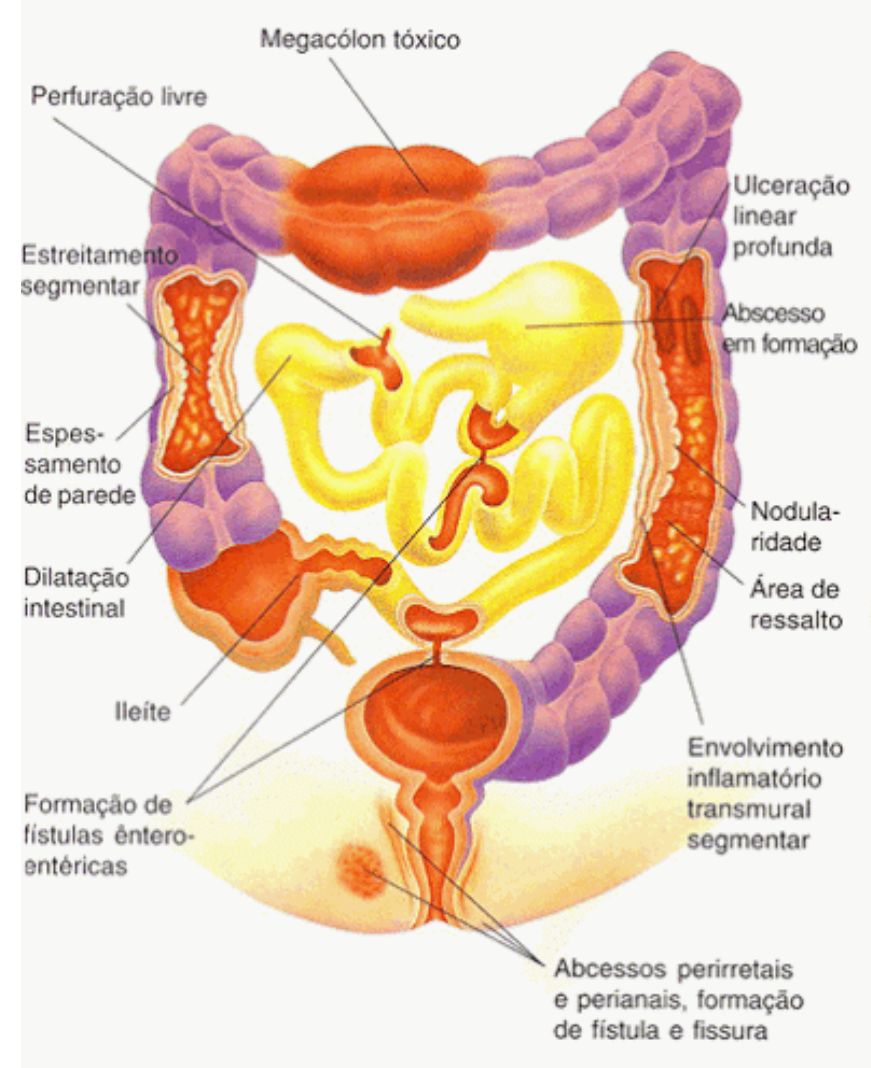

RC: 82101

Disponível em: https://www.nucleodoconhecimento.com.br/saude/modulacao-damicrobiota 
Souza (2015), chama a atenção para a predisposição genética e a alterações funcionais na resposta imunitária inata ou relacionada com respostas contra microrganismos como parte da explicação para a cronicidade do processo inflamatório na Doença de Crohn. Ele descreve a associação de polimorfismos no gene NOD2 (nucleotide-binding oligomerization domain-containing protein 2), também conhecido como CARD15 (caspase recruitment domain-containing protein 15) à alterações na imunidade inata, como alterações na regulação de liberação de citocinas pró-inflamatórias e na produção de peptídeos antimicrobianos, que associados a disfunções nas células de Paneth, resultariam na disfunção da barreira epitelial, sendo ainda relacionados com apoptose de células epiteliais e expressão de proteínas das componentes das tight junctions (junções firmes), principalmente da família das claudinas. Há também alteração em genes ligados a liberação de citocinas IL-12 (interleucina-12) e IL-23 (interleucina-23), que estão envolvidas na ativação de linfócitos Th1 (T- cell helpers), tendo como subproduto IFN-gama (Interferon gama) e IL-17 (interleucina-17). O gene que codifica a IL-10 tem ação imunossupressora e tem função de inibir a resposta imunitária do tipo Th1. Na Doença de Crohn foi identificada uma deficiência na produção dessa citocina e uma ativação aumentada da resposta Th1.

Na DC, os linfócitos T auxiliares apresentam tipicamente o fenótipo Th1 de resposta, com produção aumentada de INF-gama. Na mucosa intestinal dos pacientes com DC, os macrófagos que, juntamente com as células dendríticas, atuam como apresentadores de antígenos produzem grandes quantidades de citocinas indutoras, como, por exemplo, IL-12 e IL-18. Consequentemente, a ativação excessiva da resposta Th1 leva a produção de outras citocinas próinflamatórias, principalmente pelos próprios macrófagos, como TNFalfa e IL-1beta. (...) Evidências sugerem que esses linfócitos T sejam capazes de se proliferarem mais rapidamente, além de serem anormalmente resistentes à apoptose (SOUZA, 2015).

A doença de Crohn tende a acometer adultos jovens, com igual incidência em ambos os sexos, porém com predomínio em indivíduos de raça branca, particularmente caucasianos. Todavia, não é raro observar a doença em indivíduos

RC: 82101

Disponível em: https://www.nucleodoconhecimento.com.br/saude/modulacao-da- 
de meia-idade e de outras raças e etnias (SILVA; LAUDANNA, 2007). Representam um importante problema de saúde pública, já que comprometem jovens em fase economicamente produtiva e tem evolução crônica e recidivante, com redução da qualidade de vida (HALFELD, 2015). A incidência das DIl varia entre 3 e 20 casos por 100 mil pessoas por ano nos EUA e no Canadá. Em São Paulo há uma estimativa da prevalência da doença de Crohn de aproximadamente 15/100 mil habitantes (MACHADO, 2015).

Segundo a portaria oㅡ 966, de outubro de 2014, do Ministério da Saúde do Brasil, em países desenvolvidos, a prevalência e a incidência situam-se em torno de 50:100.000 e 5:100.000 respectivamente. Em São Paulo encontrou uma estimativa de 14,8 casos por 100.000 habitantes. A DC afeta, geralmente, pessoas com idade entre 20 e 30 anos, mas pode afetar qualquer faixa etária.

De modo geral, o tratamento da doença de Crohn busca o controle dos sintomas gastrointestinais da doença, as recidivas, as manifestações extra-intestinais e promover melhor qualidade de vida para o paciente. Para esse fim, o tratamento inclui dietoterapia e uso de medicação específica para controle da infecção e do sistema imunológico. Em relação a dieta, não existem alimentos específicos que devam ser evitados, indica-se uma alimentação balanceada e, de acordo com cada caso, certas orientações específicas (SILVA; LAUDANNA, 2007).

Segundo Silva; Laudanna (2007), a terapêutica medicamentosa é definida de acordo com a extensão, gravidade e localização da doença, a idade e sexo do paciente. A terapêutica medicamentosa inclui anti-inflamatórios, como Aminossalicilatos, Sulfassalazina, Mesalazina e corticoesteróides; imunossupressores, como Azatioprina/6-mercaptopurina, Ciclosporina A, Tacrolimo e Metotrexato; e antimicrobianos, como Metronidazol, Ciprofloxacino/ Claritromicina e Rifaximina; todos os fármacos com ação mais direta sobre os mediadores químicos da inflamação, ampliando as possibilidades do controle sintomático da DC (MISZPUTEN, 2015). Essas medicações podem provocar sintomas como náuseas,

RC: 82101

Disponível em: https://www.nucleodoconhecimento.com.br/saude/modulacao-damicrobiota 
vômito, dispepsia, gastrite, alteração hidroeletrolítica, excreção urinária de nitrogênio, vitaminas e minerais como zinco e vitaminas $B$, podem diminuir a síntese proteíca, interferir no metabolismo renal de vitamina $D$, causar alterações gastrointestinais e na função hepática, alteração na flora intestinal, dor abdominal, diarreia (REIS, 2004).

Segundo Miszputen (2015), vários grupos vêm descrevendo diferenças no microbioma intestinal de doentes - disbiose - quando comparados com o de indivíduos sadios; redução significativa da sua biodiversidade na DC, com as mudanças nos microrganismos dominantes; variações temporais da sua composição no intestino inflamado contra uma estabilidade permanentes controles e diferenças interindividuais em que tem inflamação; além de conter subespécies infrequentes não observadas na população saudável. Por esse motivo e pensando nos possíveis benefícios da reversão desse quadro, tem se pensado no uso de probióticos como proposta terapêutica.

As provas de atividade inflamatória são utilizadas para auxiliar no diagnóstico e no tratamento da DC. Esses marcadores podem variar de acordo com a atividade e a extensão da doença e, por isso, são usados como parâmetro na avaliação. Dentre os exames bioquímicos que podem ser utilizados com essa finalidade estão velocidade de hemossedimentação (VHS), proteína C reativa (PC-R), Alfa-1 glicoproteína ácida, seromucóides, fibrinogênio, haptoglobina, porém os mais utilizados na clínica são VHS e PC-R. Esses marcadores são considerados inespecíficos, pois podem se mostrar alterados em outras patologias. Há também os marcadores fecais como a Calprotectina fecal, elastase de polimorfonucleares e alfa1-antitripsina, cujos resultados julga-se mais fidedigno devido ao contato direto das fezes com a mucosa intestinal (ZALTMAN et al., 2015).

RC: 82101

Disponível em: https://www.nucleodoconhecimento.com.br/saude/modulacao-damicrobiota 


\subsection{MICROBIOTA INTESTINAL}

O corpo humano abriga uma variedade enorme de microrganismos, principalmente bactérias, que habitam a boca, a pele, a cavidade nasal, faringe, estomago, intestinos e trato urogenital. Essa população microbiana constitui o que chamamos de microbioma humano, onde os dois maiores são a microbiota bucal e a intestinal. Sabe-se que a quantidade de células que constituem o microbioma é maior que o número total de células do próprio hospedeiro (HARTH-CHÚ et al., 2013; MACHADO et al., 2015). O interesse pelo estudo do microbioma surgiu após identificarem as funções que ele desempenha no organismo hospedeiro através da interação simbiótica capaz de interferir no estado de saúde do indivíduo (MACHADO et al., 2015).

A microbiota começou a ser estudada em grande escala no início do século XXI dentro de grandes projetos como o Projeto Microbioma Humano (HMP), financiado pelo Instituto Nacional de Saúde nos Estados Unidos, e o Metagenoma do Trato Intestinal Humano (MetaHIT), financiado pela Comunidade Européia. Buscavam catalogar os microrganismos a nível de espécie através da comparação do RNA identificado com as informações na base de dados (PELAEZ; REQUENA, 2017). Esses projetos buscavam esclarecer o grau de estabilidade e resiliência da microbiota de um indivíduo ao longo do dia e durante toda a vida, se existe um nível de similaridade entre os microbiomas de indivíduos de uma mesma família ou de uma comunidade, ou ainda entre comunidades de diferentes ambientes, identificar o que afeta a diversidade genética do microbioma e como esta interfere na adaptação dos microrganismos a hospedeiros com estilos de vida diferentes e com vários estágios fisiológicos e fisiopatológicos (MACHADO, 2015).

A microbiota intestinal é influenciada por fatores intrínsecos do hospedeiro genótipo, idade, condições de saúde e nutrição -, por interações com outros

RC: 82101

Disponível em: https://www.nucleodoconhecimento.com.br/saude/modulacao-damicrobiota 
microrganismos e pela disponibilidade de nutrientes da dieta (PAIVA; MANTOVANI, 2015).

A ideia de que a colonização se inicia no parto tem sido questionada. Novos estudos têm apontado para a possibilidade de colonização acontecer no feto, durante a gestação. Ainda não se sabe qual é o momento exato em que o processo de colonização inicia, nem o mecanismo exato da transferência bacteriana da mãe para o feto. $O$ trato gastrointestinal materno é a fonte mais provável, pois há indícios de que a microbiota intestinal da mãe modula a microbiota do feto. A translocação bacteriana do intestino para o sangue e deste para outros órgãos aumenta durante a gravidez e amamentação. Além disso, bactérias ou DNA bacteriano são transportados por células mononucleares do sangue da mãe com maior frequência e diversidade durante a gestação e são encontradas nas fezes do bebê, o que também sugere a ocorrência de transferência de bactérias durante 0 desenvolvimento do feto no útero e favoreça o desenvolvimento de uma resposta imunológica equilibrada no bebê após o nascimento. (KEELER; WEITKAMP, 2015; PEREZ et al., 2007)

Keeler; Weitkamp (2015), concluíram que pode haver uma colonização da mãe para o feto durante a gestão após encontrarem uma certa variedade microbiana em uma amostra de mucosa intestinal retirada de bebês logo após o nascimento, de parto cesária, e antes da primeira alimentação, e comparar a composição microbiana da mucosa intestinal com a encontrada nas fezes do bebê e verificar que a diversidade era maior na amostra de mucosa.

O tipo de parto e o tempo de gestação são uma das primeiras formas de colonização e influenciam na diversidade microbioma. Bebês que nascem de cesariana tem microbiota diferente daqueles que nasceram de parto vaginal e a colonização é mais lenta. Bebês nascidos de parto vaginal tem microflora composta por uma quantidade de Bifdobactérias mais elevada. Nos primeiros 2 dias de vida o TGI é rapidamente colonizado, principalmente por enterobactérias. A alimentação influencia na

RC: 82101

Disponível em: https://www.nucleodoconhecimento.com.br/saude/modulacao-da- 
composição da microflora, gerando aumento de Bifdobactérias, em maior quantidade, Lactobacillus e Bacterióides, em menor quantidade, à medida que estas aumentam a população de enterobactérias diminui. Dessa forma, bebês alimentados por leite materno tem microbiota majoritária de Bifdobactérias e contém Lactobacillus e Staphylococcus em menor quantidade, bebês, com idade entre 1 e 4 meses, alimentados por fórmula possuem uma microflora mais complexa predominante de coliformes e Bacterióides. Com a diversificação alimentar a microflora do bebê começa a se assemelhar a do adulto, variando de indivíduo para indivíduo, mas permanecendo relativamente estável no próprio indivíduo (KEELER; WEITKAMP, 2015; CANÁRIO, 2012).

As bactérias da microflora podem ser encontradas por todo o trato gastrointestinal e essa composição varia em cada região de acordo com as condições que a área oferece para seu desenvolvimento. A densidade populacional de cada espécie é regulada por um estado competitivo por nutrientes e espaço entre a microflora residente e a transitória, essa relação é responsável por controlar o crescimento de bactérias patogênicas e pela manutenção do estado de saúde do indivíduo (REIS, 2003).

RC: 82101

Disponível em: https://www.nucleodoconhecimento.com.br/saude/modulacao-damicrobiota 
Figura 2 - Colonização microbiana do trato gastrointestinal

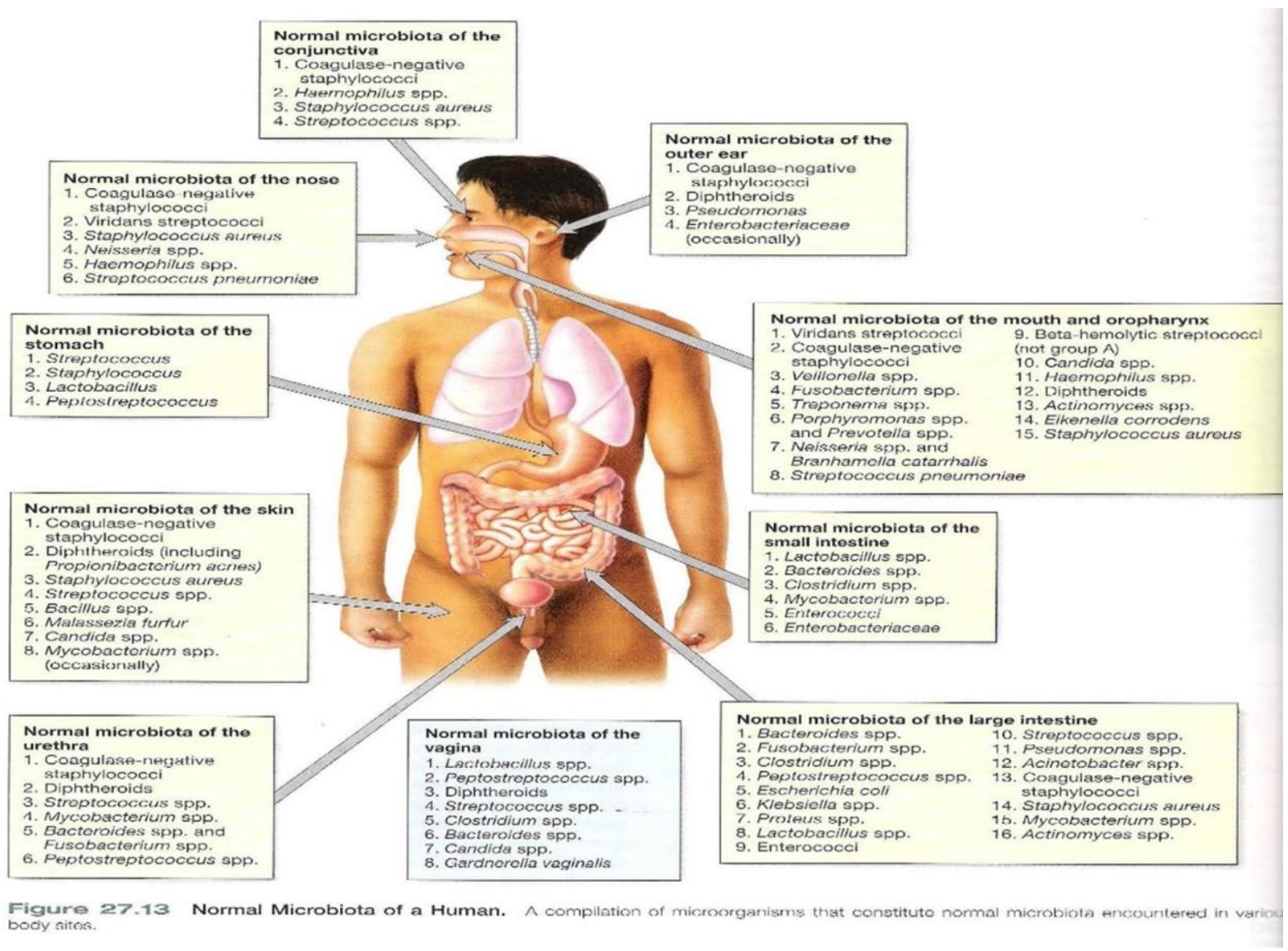

A microflora do cólon é a mais numerosa do intestino. Em relação aos tipos de bactérias, trata-se de uma população diversificada, envolvendo bactérias anaeróbicas e coliformes, sendo as espécies mais numerosas as Bacterióides, Clostridium, Bifdobacterium, Pseudomonas, Streptococcus, Lactobacillus, Fusobactérias, Enterobacteriaceae e Staphylococcus. A microbiota do Jejuno e Íleo é menos numerosa que a do cólon, também predominam bactérias anaeróbicas e coliformes, sendo as espécies mais numerosas os Lactobacillus, Bacterióides, Enterobacteriaceae, Bifidobacterium, Streptococcus e Fusobactérias (REIS, 2003). Segundo Souza (2015), foi identificado um aumento especificamente de Escherichia coli aderente-invasiva na mucosa de pacientes de DC com comprometimento ileal.

RC: 82101

Disponível em: https://www.nucleodoconhecimento.com.br/saude/modulacao-damicrobiota 
A microflora pode ser classificada conforme a sua composição, em residente e transitória - constituída por bactérias anaeróbicas e de bactérias não-residentes, dependentes da composição da microflora residente e de outros fatores para se desenvolverem -, e microflora normal ou nativa - composta por bactérias anaeróbicas e aeróbicas residentes, "estáticas" -, ou classificadas de acordo com a patogenicidade, em não-patogênica, por não induzir estado patológico em indivíduos saudáveis e induzem ou mantém um estado de tolerância oral à microflora e impede a indução de uma resposta inflamatória local; potencialmente patogênica ou oportunista, em indivíduos saudáveis são controladas pelo tecido linfóide associado ao intestino (GALT), por fatores defensivos inespecíficos e pela flora nãopatogênica, mas pode causar doença em indivíduo comprometido; e microflora patogênica, que após contaminação em número suficiente pode causar inflamação e infecção com sinais e sintomas identificáveis em indivíduos saudáveis (REIS, 2003).

A microbiota tem função de imunomoduladora, auxilia na nutrição e metabolismo, função de proteção, auxilia na manutenção da estrutura e funcionamento do TGl. (MOREIRA; BARRA, 2015) Algumas espécies dessas bactérias são capazes de produzir ácidos graxos de cadeia curta (AGCC), principalmente 0 acetato, o butirato e o propionato, a partir de carboidratos não digeríveis da dieta. $\mathrm{Na}$ falta de carboidratos, as bactérias podem usar aminoácidos de cadeia ramificada, mas também dá origem a ácidos graxos de cadeia ramificada, como isobutirato, 2metilbutirato e isovalerato. Cepas de Faecalibacterium prausnitzii, Eubacterium retale, Eubacterium hallii, Butyricicoccus pullicaecorum e $R$. bromii, do filo Firmicutes, parecem ser responsáveis pela maior parte da síntese de butirato, sendo este último o que mais produz butirato a partir de amido resistente e sua ausência é um determinante na redução da produção de butirato a partir de amido resistente. $\mathrm{O}$ F. prausnitzii, mesmo sendo anaeróbio estrito consegue crescer em ambiente com pouco oxigênio se houver vitamina $B_{2}$, cisteína ou glutationa e usa, preferencialmente Inulina e pectina, ao invés de usar amido e hemicelulose para síntese de butirato. O F. prausnitzii corresponde a 5 a $20 \%$ da composição da

RC: 82101

Disponível em: https://www.nucleodoconhecimento.com.br/saude/modulacao-damicrobiota 
microbiota saudável e uma redução na quantidade dessa espécie tem sido associada ao desenvolvimento de Doença de Crohn. O butirato é o AGCC de maior quantidade no intestino e vai atuar como fonte energética, como reguladores da expressão gênica, como moléculas de sinalização reconhecidas por receptores específicos em uma grande variedade de células, inclusive enteroendócrinas e imunológicas, imunorreguladores, aumentando a tolerância do sistema imunológico às bactérias comensais residentes no intestino e diminuindo inflamação. (LOUIS; FLINT, 2017; MORRISON; PRESTON, 2016;KOH et al., 2016)

Figura 3 - Funções da Microbiota

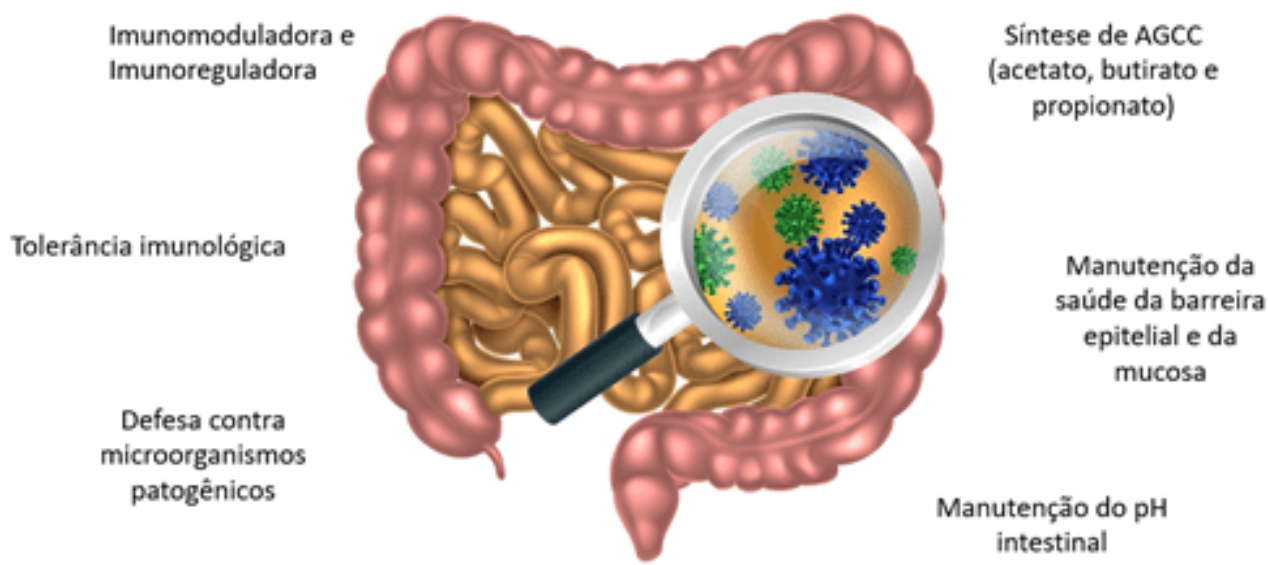

Fonte: AUTORA (2020)

Segundo Stagg (2018), a tolerância intestinal e a homeostase intestinal dependem de um equilíbrio entre a função dos conjuntos distintos existentes de células dendríticas e a microbiota intestinal. Essas células participam de vários processos de regulação, desde apresentação de antígenos e integrantes da microbiota comensal às células $T$ efetoras até ativação celular de células Treg. Essas células

RC: 82101

Disponível em: https://www.nucleodoconhecimento.com.br/saude/modulacao-damicrobiota 
estão divididas em dois grandes grupos: células dendríticas clássicas (CDc) e células dendríticas plasmocitárias. As células dendríticas clássicas do intestino são capazes de expressar a enzima RALDH2, que é necessária para sintetizar ácido retinóico a partir de vitamina $A$ oriunda da dieta, que vai ser usado na diferenciação de linfócitos $T$ naive em Treg. As CDc dependem da expressão de integrinas específicas para promover a ativação do TGF-beta latente e do ácido retinóico para promover a geração de Treg. Arpaia et al. (2013), após experimento in vitro com CDs, concluíram que o butirato age sobre as CDs estimulando a expressão de Foxp3 através da inibição de histonas desacetilases para promover a diferenciação de T naives em Treg fora do Timo.

As células epiteliais (CEs) da barreira participam ativamente do processo de tolerância imunológica, contribuindo com síntese de ácido retinóico e atuando na maturação das CDs para induzi-las na ativação de Treg. Quando as CDs entram em contato com as CEs, ocorre liberação da enzima aldh1a2 que vai promover a síntese de ácido retinóico (AR). O desenvolvimento da tolerância por parte das CDs é dependente do TGF-beta e do ácido retinóico sintetizado pelas CEs, e a ausência de qualquer um desses fatores é suficiente para influenciar negativamente na diferenciação das Treg. É o ácido retinóico das CEs que promovem a diferenciação em Treg e suprime respostas inflamatórias do tipo Th17. Se, por algum motivo, essa síntese de AR for comprometida, a resposta inflamatória é restaurada.

RC: 82101

Disponível em: https://www.nucleodoconhecimento.com.br/saude/modulacao-damicrobiota 
Figura 4 - Diferenciação de CD de mucosa e ativação de T naives em Treg

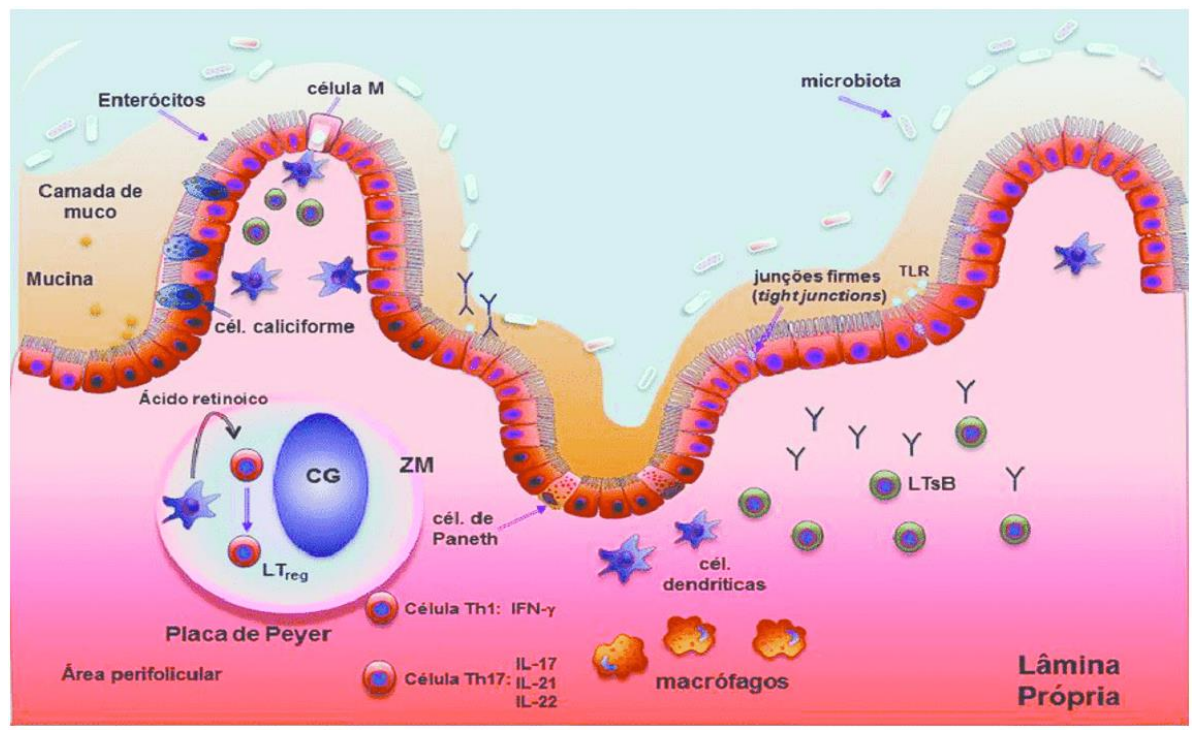

Fonte: ORIÁ, [S.I.]

As células Treg tem um papel protetor contra a doença inflamatória intestinal devido sua ação supressora de citocinas inflamatórias. (ILIEV et al., 2009) Segundo Melo; Carvalho (2009), as Treg são um grupo de linfócitos T, que expressam a molécula $\mathrm{CD}_{25} 5^{+}$e fator nuclear FOXP3, e agem promovendo tolerância imunológica, ou seja, uma ausência de resposta ao encontrar um antígeno ao qual ela já tenha sido anteriormente apresentada, impedindo a ativação de células $T$ efetoras e suprimindo a função destes, regulando a resposta contra antígenos invasores ou do próprio organismo. Elas estão divididas em Treg naturais, ativadas no Timo, e Treg adaptativas, ativadas na periferia em condições tolerogênicas. Estas últimas atuam liberando IL-10, que vai bloquear a ativação de células apresentadoras de antígeno e inibir a ação de INF-gama, e TGF-beta, que vai ter ação supressora e estimular a expressão de FOXP3 para transformar T naives em Treg.

RC: 82101

Disponível em: https://www.nucleodoconhecimento.com.br/saude/modulacao-damicrobiota 


\subsection{DISBIOSE INTESTINAL X INFLAMAÇÃO}

Moreira; Barra (2015) definem disbiose como sendo um desequilíbrio na microbiota com predomínio de bactérias potencialmente patogênicas sobre as benéficas.

Mizsputen (2015), acrescenta que vários grupos vêm descrevendo diferenças no microbioma intestinal de doentes - disbiose - quando comparados com o de indivíduos sadios, apresentam redução significativa de sua biodiversidade na DC, com as mudanças nos microrganismos dominantes; variações temporais da sua composição no intestino inflamado contra uma estabilidade permanente nos controles e diferenças interindividuais em que tem inflamação; além de conter subespécies infrequentes não observadas na população saudável.

As principais causas para que essas alterações ocorram são o uso indiscriminado de medicamentos, como antiácidos, anti-inflamatórios, laxantes, anticoncepcionais, estrógenos e corticóides; estresse, radiação, excessiva exposição a toxinas ambientais, determinados componentes e padrões alimentares; idade, estado imunológico do paciente, $\mathrm{pH}$ intestinal, hipocloridria gástrica e tempo de trânsito intestinal. Na vigência de disbiose intestinal, pode ocorrer perda de funções importantes para o hospedeiro. As alterações qualitativas e quantitativas na microbiota intestinal, além de alterações nas atividades metabólicas e na distribuição de bactérias ao longo do intestino, associam-se a diversas condições como: diarreias, déficits nutricionais, doença celíaca, câncer colorretal, doenças inflamatórias intestinais, síndrome do cólon irritável e supercrescimento bacteriano; pode provocar aumento da permeabilidade intestinal, alterando uma importante função da mucosa intestinal que é a atividade de barreira (MOREIRA; BARRA, 2015).

O supercrescimento bacteriano acontece quando se alteram mecanismos reguladores na microbiota intestinal com consequente proliferação de bactérias colônicas no intestino delgado, sobretudo em segmentos ileais, consequentemente

RC: 82101

Disponível em: https://www.nucleodoconhecimento.com.br/saude/modulacao-da- 
interferindo nos processos digestivos e absortivos. A redução do trânsito intestinal promovida por uso de fármacos antidiarreicos e antiácidos, e como consequência de intervenção cirúrgica também vão promover crescimento da população bacteriana e reduzir a capacidade de eliminação pelas ondas peristálticas (MOREIRA; BARRA, 2015).

Souza (2015), também aponta essa alteração qualitativa e quantitativa na composição da microbiota - disbiose - como fator para ativação da DC e chama atenção para uma inconsistência de dados, enquanto um grupo de investigadores revelou um número aumentado especificamente de Escherichia coli aderenteinvasiva na mucosa de pacientes com DC com comprometimento ileal, alguns trabalhos indicaram haver diminuição, outros sugeriram aumento da diversidade da microbiota intestinal de pacientes com DII. Morrison; Preston (2016) também citam uma redução da diversidade microbiana e uma perda de bactérias produtoras de butirato em portadores de doença inflamatória intestinal. Sitkin; Vakhitov; Pokrotnieks (2018), também identificaram uma redução de bactérias butirogênicas em portadores de Colite Ulcerativa (CU). Laserna-Mendieta et al. (2018), encontraram resultado semelhante ao comparar o conteúdo gênico BCoAT da microbiota de portadores de DC ativa e inativa com portadores de CU ativa e inativa e pessoas saudáveis, sendo uma quantidade menor nos portadores de DC e CU, em relação aos controles saudáveis, e ainda menor em portadores de DC, se comparados com portadores de CU, sendo menos prevalente nos portadores de DC ativa, além disso identificou forte correlação com essa redução e o aumento de marcadores inflamatórios, onde, quanto maior a inflamação, menor a presença de bactérias butirogênicas

RC: 82101

Disponível em: https://www.nucleodoconhecimento.com.br/saude/modulacao-da- 
Figura 5 - Fatores e Consequências da Disbiose

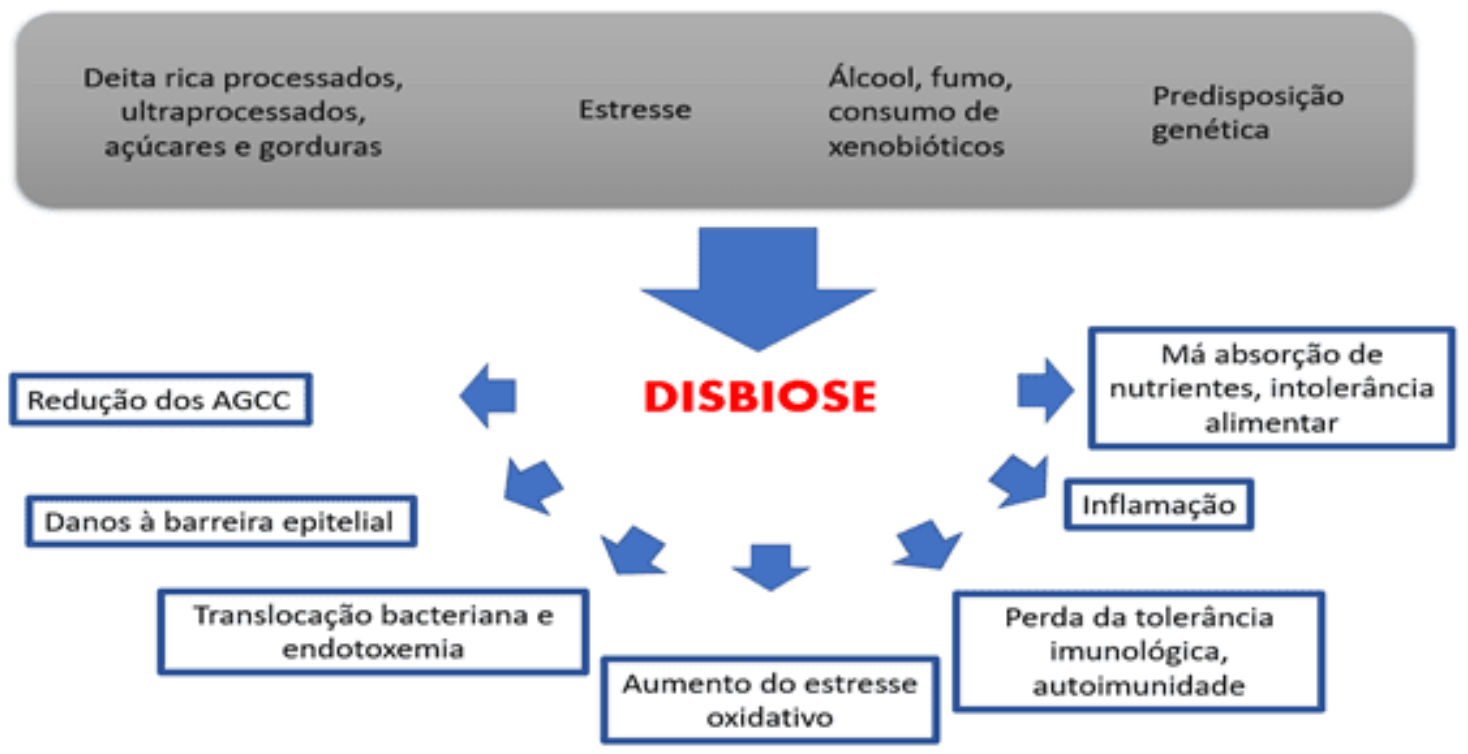

Fonte: AUTORA (2020)

Segundo Qiang et al. (2017), o butirato e o ácido retinóico participam da diferenciação das células dendríticas (CDs) de mucosa e essas células participam do desenvolvimento da imunidade intestinal, promovendo tolerância, através da ativação de células $T$ naive em Células $T$ reguladoras (Treg), inibindo a diferenciação em células $T$ efetoras e aumentando a expressão de citocinas antiinflamatórias, ou inflamação, na ausência desses substratos, com maior ativação de células $T$ efetoras, onde a disbiose poderia promover uma desregulação nesse sistema e favorecer o surgimento de doença inflamatória intestinal. Segundo Melo; Carvalho (2009), nas doenças autoimunes as Tregs podem estar reduzidas em número ou estarem funcionalmente alteradas. Zhou et al. (2019), diz que na DC a quantidade de Treg é reduzida devido haver também redução de IL-2, uma citocina necessária para evitar o desenvolvimento de inflamação crônica no trato gastrointestinal, sintetizada por células linfóides inatas do grupo 3 no intestino delgado, que dependem da liberação de IL-1beta por macrófagos, que, por sua vez,

RC: 82101

Disponível em: https://www.nucleodoconhecimento.com.br/saude/modulacao-damicrobiota 
precisam detectar microbiota dependente de MyD88 e NOD2, este último um gene com polimorfismos associados ao desenvolvimento da DC.

Figura 6 - Processo de ativação de Treg mediado por ácido retinóico e butirato

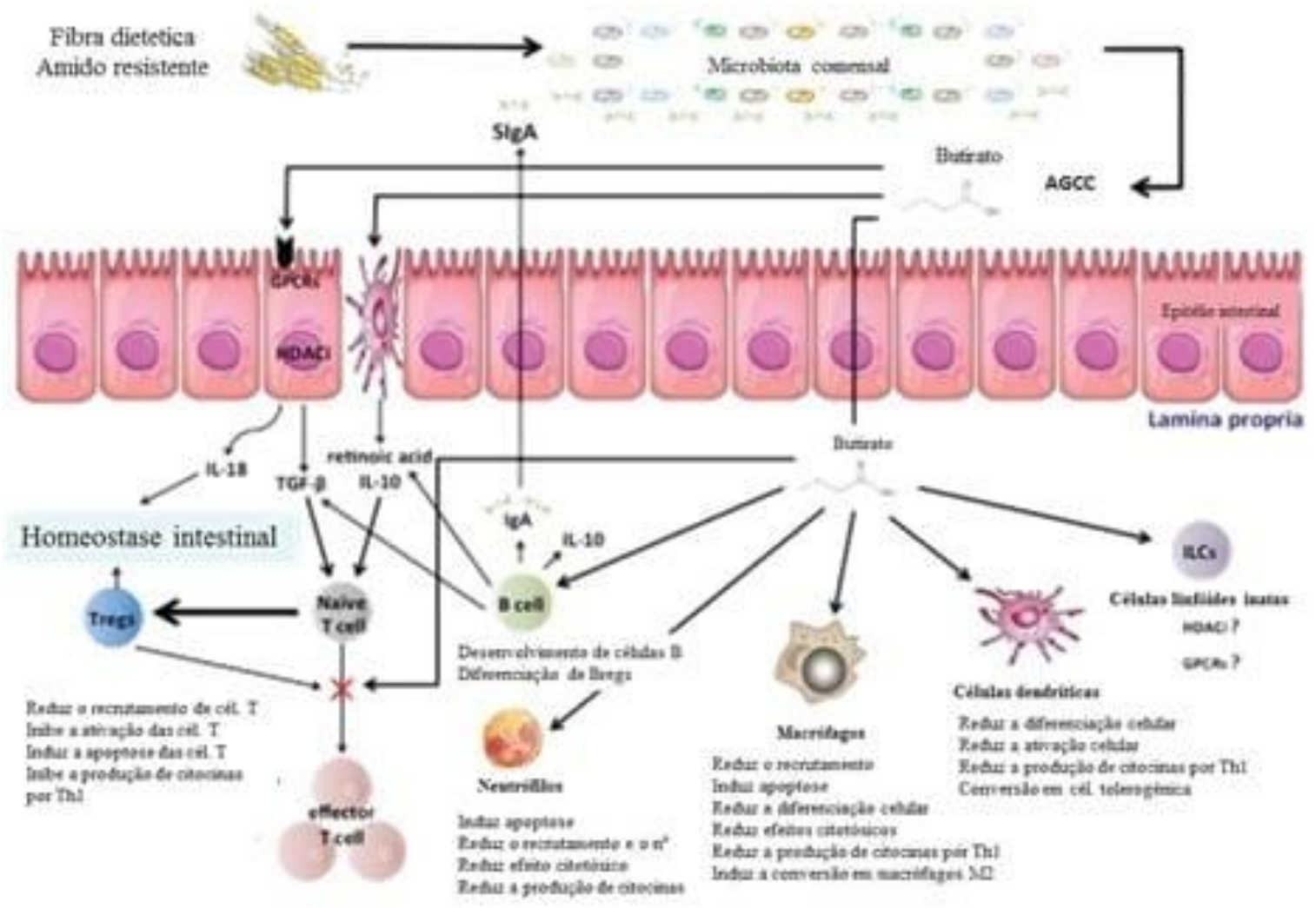

Fonte: Meurer, 2018

\subsection{MODULAÇÃO DA MICROBIOTA INTESTINAL}

\subsubsection{MODULAÇÃO INTESTINAL COM DIETA}

Dentre os fatores que influenciam na patogênese da DIl estão a composição da microbiota intestinal, a desregulação do sistema imune e a dieta ao estilo ocidental, uma dieta mais calórica, rica em gorduras, com maior consumo de carne vermelha e alimentos processados, com teor elevado de ômega 6 e com baixo consumo de

RC: 82101

Disponível em: https://www.nucleodoconhecimento.com.br/saude/modulacao-damicrobiota 
frutas e legumes. (CASTRO et al., 2020) Sakamoto et al. (2005), realizaram um estudo multicêntrico de controle de caso no Japão com portadores de CU e DC, entre 15 e 34 anos de idade e que obtiveram o diagnóstico da doença em até 3 anos, a fim de avaliar o hábito alimentar nos 5 anos anteriores ao diagnóstico para correlacionar a alimentação com o risco de desenvolver DII e encontrou correlação positiva para o consumo de gorduras, óleos, açúcares e adoçantes tanto em $\mathrm{CU}$ quanto em DC, e o consumo de mariscos e peixes para DC. Além disso, também identificou o consumo de vitamina $\mathrm{C}$ como um fator protetor para o desenvolvimento de DII, e maior consumo de vitamina E como fator de risco. Castro et al. (2020), realizou um estudo transversal com 60 pacientes com DC no íleo ou no cólon, sendo 31 em remissão e 29 em atividade, com idade entre 18 e 60 anos, por 6 meses, e verificou uma associação entre uma dieta tradicional do brasileiro, composta de alimentos cárneos, carboidratos simples, derivados de leite, ovos, e FOODMAPs, leguminosas como o feijão, com maior número de sintomas (5 ou mais sintomas) e número de cirurgias, sugerindo que, devido a melhora física sentida após a cirurgia o portador da DIl opte por uma restrição muito menor na dieta, incluindo FOODMAPs, que podem causar sintomas abdominais mesmo que a doença esteja em remissão.

O consumo de FOODMAPs tem sido associado ao desenvolvimento de sintomas gastrointestinais como distensão abdominal, diarreia e/ou constipação, dor abdominal e flatulência. A dieta pobre em FOODMAPs está relacionada a uma redução desses sintomas, e a uma redução na quantidade de cepas envolvidas na regulação da resposta imunológica. (CASTRO et al., 2020) Cox et al. (2020), encontraram resultado semelhante em um estudo realizado com 52 portadores de DC em atividade e CU sintomática, tratados com dieta low FOODMAPs por 4 semanas, onde obtiveram redução dos sintomas, melhora da qualidade de vida, e redução do número de cepas de Bifdobacterium adolescentes, Bifdobacterium longum e Faecalibacterium prausnitzii, mas essa redução da diversidade da microbiota não impactou negativamente na inflamação.

RC: 82101

Disponível em: https://www.nucleodoconhecimento.com.br/saude/modulacao-damicrobiota 
A diversidade e a estabilidade da comunidade microbiana do intestino estão em constante adaptação e mudança em resposta as alterações na composição da alimentação do hospedeiro. Essa relação entre dieta e a composição da microflora interfere no metabolismo tanto da microbiota quanto do hospedeiro (PAIVA; MANTOVANI, 2015).

Uma dieta rica em fibras e vegetais está associada a uma maior população de bacteróides e firmicutes, redução de marcadores inflamatórios e maior excreção de butirato nas fezes. As flavinas, forma de coenzima da riboflavina nos alimentos, e tióis, presentes na cisteína e glutationa, influenciam no crescimento de cepas de $F$. prausnitizii, uma bactéria anaeróbia produtora de butirato, em um ambiente com oxigênio. Produtos lácteos, fibras, vegetais verde escuro, carnes e peixes são as principais fontes de flavinas para o intestino, já os tióis são encontrados na gema de ovo, laticínios e grãos. (FARIAS; THIEME; HEYDE, 2016; KHAN et al., 2012; LOUIS; FLINT, 2017; WILSON; WHELAN, 2017)

Um estudo mostrou que pacientes com DC e menos gene BCoAT, gene cuja expressão está associada a produção de butirato, tinham uma alimentação com maior concentração de carboidratos simples, como pão branco e açúcares, e pobre em vegetais, frutas e cereais integrais. Os pacientes que tinham uma expressão maior de BCoAT ingeriam mais nozes do que os que tinham menos BCoAT. (LASERNA-MENDIETA et al., 2018) Laserna-Mendieta et al. (2018), concluíram que a modulação da microbiota pela dieta pode ser mais eficaz e consistente do que a suplementação direta de butirato ou de prebióticos para aumentar as concentrações desse AGCC e considera que incluir na dieta alimentos fonte de amido resistente, farelo de aveia, sorbitol, ácido galcturônico e glucurônico, inulina e FOS sejam os mais efetivos para estimular a síntese de butirato. Segundo Wilson; Whelan (2017), há evidências de que uma dieta rica em fibras e vegetais, por tanto rica em oligossacarídeos, tem efeito sobre a microbiota, mas não um efeito específico, e por

RC: 82101

Disponível em: https://www.nucleodoconhecimento.com.br/saude/modulacao-da- 
isso não pode ser considerada prebiótica, porém não se pode ignorar os benefícios à saúde.

Boneh et al. (2017), obtiveram resultados positivos em pacientes com DC utilizando dieta de exclusão (DE) combinada com 50\% do aporte calórico em nutrição enteral parcial (NEP) polimérica via oral. Os casos mais graves eram inicialmente tratados com nutrição enteral exclusiva por sonda nas primeiras 2 semanas e depois passava para NEP e DE. A dieta em teste continha frutas, carboidratos complexos e simples, carnes e vegetais. Frutas contendo amido resistente e alimentos específicos de proteína animal tinham consumo obrigatório. Limitava ou excluía alimentos com potencial para causar disbiose intestinal, como gorduras de origem animal, certos cortes e tipos de carnes, glúten, maltodextrina, goma xantham, emulsificantes, sulfitos e alguns monossacarídeos. A duração do estudo é de 12 semanas, onde nas primeiras 6 semanas a dieta seria mais restrita e teria o objetivo de alcançar a remissão dos sintomas. Quatro dos vinte e um pacientes analisados optaram por não tomar a fórmula líquida e fazer apenas a dieta de exclusão. Dos que fizeram apenas a dieta, 3 alcançaram a remissão. Além da remissão da doença e do controle dos sintomas, houve uma diminuição significativa nos marcadores inflamatórios analisados (PCR e Calprotectina). Por causa desse resultado, concluíram que a dieta foi o fator mais decisivo na redução da inflamação e não a NE.

A nutrição enteral exclusiva (NEE), considerada a dieta mais eficaz para induzir remissão na DC, mas também gera alterações na microbiota, tanto funcionais, interferindo na produção de metabólitos, quanto quantitativamente na composição desta. (MACLELLAN et al., 2017). Walton et al. (2017), avaliaram pacientes com DC após duas semanas de NEE e identificaram melhora dos sintomas, redução dos níveis de PCR, menor excreção de AGCC nas fezes e de outros metabólicos tóxicos. Gerasimidis et al. (2014), encontraram resultados semelhantes em 15 crianças com DC e 21 controles saudáveis, após 60 dias de NEE. Observaram uma redução da

RC: 82101

Disponível em: https://www.nucleodoconhecimento.com.br/saude/modulacao-damicrobiota 
produção de butirato, aumento de $\mathrm{pH}$ fecal e de sulfeto, além disso também houve redução da presença de $F$. prausnitzii e de Bacterioides/Prevotella, porém a diversidade microbiana voltou as concentrações originais pré-enteral assim que foi restabelecida dieta livre. Esses efeitos foram atribuídos a redução da ingestão de fibras da dieta enteral e a uma mudança do catabolismo de carboidratos para o proteico. Segundo um estudo realizado com 23 crianças com DC em NEE por Quince et al. (2015), a cada 10 dias em NEE aumenta a perda de diversidade da microbiota em 0,6 equivalentes, porém, após retornar a dieta livre a diversidade volta ao estágio inicial e a inflamação aumenta proporcionalmente. Outro dado relevante nesta pesquisa é que antes da NEE a diversidade de gêneros já era menor que nos controles saudáveis, apontando para uma redução de grupos de bactérias protetoras como Faecalibacterium e Bifidubacterium, Ruminococcus, e a funcional da microbiota era maior nos portadores de DC, e após a NEE a redução da diversidade se tornou ainda maior, principalmente nos gêneros que já estavam reduzidos, aumentando a disbiose ao invés de reduzí-la, e houve também uma redução funcional significativa da microbiota dos portadores de DC igualando a diversidade funcional dos controles, sinalizando uma possível redundância funcional na microbiota de portadores de Crohn, durante a terapia com NEE. Além disso, neste estudo ficou evidenciado a calprotectina e o Índice de Atividade Pediátrica de Crohn (PCDAI) como melhores indicadores de disbiose intestinal. (QUINCE et al., 2015)

Devido à dificuldade de aceitação da NEE por adultos, quase não se tem estudos em adultos sobre essa dieta e a maioria dos estudos são feitos com pequenos grupos de crianças. (SVOLOS et al., 2019) Svolos et al. (2019), desenvolveram uma dieta baseada em alimentos individualizada (CD-TREAT), baseada na composição de NEE - inspirada no Modulen IBD, sem glúten, lactose e álcool, com distribuição de macronutrientes semelhante ( em torno de $40 \%$ de lipídios, $18 \%$ de proteína, $42 \%$ de carboidratos, e $5 \%$ de fibras) e com carboidratos ricos em amido resistente em substituição a maltodextrina -, testaram em adultos e crianças com Crohn, que receberam NEE ou CD-TREAT por uma semana, observaram resultados

RC: 82101

Disponível em: https://www.nucleodoconhecimento.com.br/saude/modulacao-damicrobiota 
semelhantes entre os pacientes que ingeriram NEE e os que ingeriram CD-TREAT, apresentando redução da síntese de butirato, acetato e propionato a partir de carboidratos e um aumento da síntese de ácidos graxos ramificados aumentaram após a NEE, mas o valerato reduziu apenas após a CD-TREAT, uma redução da concentração bacteriana, mesma variação da diversidade microbiana nos dois casos, o pH fecal ficou mais alcalino, também teve aumento da síntese de sulfeto, porém todas essas alterações eram revertidas e voltavam as condições iniciais assim que as intervenções foram interrompidas, ou seja, resultados semelhantes ao descrito anteriormente no estudo de Quince et al. (2015), onde verificou um perfil de microbiota disbiótico, mas, contraditoriamente, reduzindo o quadro inflamatório e a atividade da doença em crianças com DC ativa. Segundo Svolos (2019)

A aceitabilidade do NEE e o uso a longo prazo, particularmente em pacientes adultos, podem ser limitados pelo cansaço do paladar e pela palatabilidade fraca. Neste estudo, o CD-TREAT classificou-se como mais palatável, mais fácil de seguir, mais saciante e causando menos efeitos colaterais gastrointestinais que o EEN.

\subsubsection{MODULAÇÃO INTESTINAL COM BUTIRATO}

O butirato é uma importante fonte energética para as células intestinais, além de contribuir para a manutenção da barreira intestinal e ter propriedades antiinflamatórias. É sabido que há uma redução na síntese desse ácido graxo de cadeia curta em portadores de DII, sendo por tanto uma alternativa ao controle dos sintomas e inflamação sua suplementação para correção dessa deficiência. (SITKIN; VAKHITOV; POKROTNIEKS, 2018). Segundo Laserna-Mendieta et al. (2018), o interesse em pesquisas com suplementação de butirato em portadores de doenças inflamatórias se deve ao fato dele ter ação anti-carcinogênica, anti-lipogênica e antiinflamatória, é capaz de inibir a resposta inflamatória por reduzir a liberação de citocinas pró-inflamatórias através da inativação do fator de transcrição NF-kB nas células do sistema imunológico, além de participar da comunicação celular do sistema imune e inativar histonas desacetilases, favorecendo a ativação de células T

RC: 82101

Disponível em: https://www.nucleodoconhecimento.com.br/saude/modulacao-damicrobiota 
reguladoras e a homeostase. Sitkin; Vakhitov; Pokrotnieks (2018), realizaram um estudo aberto e randomizado com um grupo pacientes com Colite Ulcerativa ativa e um grupo controle de pessoas saudáveis, onde receberam suplementação de butirato de cálcio e inulina por via oral durante 28 dias, como complemento à medicação do paciente, e observaram que a suplementação foi capaz de aumentar significativamente a quantidade de bactérias butirogênicas, reduzir marcadores inflamatórios e promover a melhora dos sintomas, mostrando bem tolerado e seguro.

\subsubsection{MODULAÇÃO INTESTINAL COM PROBIÓTICOS}

Probióticos podem ser definidos como um suplemento alimentar composto por microrganismos vivos com efeitos benéficos ao organismo do hospedeiro, promovendo o equilíbrio microbiano da microflora intestinal, geralmente provenientes de mono ou múltiplas culturas de microrganismos vivos representados principalmente por Lactobacillus, Bifdobacterium, Enterococcus e Streptococcus (REIS, 2013).

Na RDC 243/2018 consta a seguinte definição de probiótico: "microrganismo vivo que, quando administrado em quantidades adequadas, confere um benefício à saúde do indivíduo". Para um microrganismo ser considerado probiótico precisa que o número de células viáveis deve atender a concentração mínima exigida até o momento do consumo (MACEDO et al; 2008 apud SBRT, 2014) e manter essa viabilidade no ecossistema digestivo afim de cumprir sua função (PROBIÓTICOS, 2010 apud SBRT, 2014). Além da viabilidade, também é avaliado a segurança do consumo do microrganismo, ou seja, deve-se apresentar estudos que comprovem que o probiótico não compromete a homeostase intestinal e em caso de serem identificados produção fatores de virulência deve-se comprovar sua segurança; a eficácia, comprovando que contribui para a saúde do trato gastrointestinal, conforme alegação geral que deve constar no dossiê técnico-científico exigido pela Anvisa para aprovação de cepas para uso como probióticos (ANVISA, 2017). A Anvisa

RC: 82101

Disponível em: https://www.nucleodoconhecimento.com.br/saude/modulacao-damicrobiota 
reconhece como probióticos Lactobacillus acidophilus, Lactobacillus casei shirota, Lactobacillus casei variedade rhamnosus, Lactobacillus casei variedade defensis, Lactobacillus paracasei, Lactococcus lactis, Bifidobacterium bifidum, Bifidobacterium animallis (incluindo a subespécie B. lactis), Bifidobacterium longum e Enterococcus faecium. A dose mínima viável determinada pela Anvisa para probióticos é de $10^{8} \mathrm{e}$ $10^{9}$ UFC na recomendação diária do produto, conforme indicação do fabricante. (ANVISA, 2008 apud SBRT, 2014). Segundo a Word Gastroenterology Organisation (WGO) (2017), não existe uma quantidade exata de probiótico a ser administrada para se conseguir os efeitos benéficos da modulação, sendo necessário uma quantidade maior para algumas cepas e uma quantidade menor para outras.

Diante do quadro de disbiose presente na DC, passa a ser interessante tentar uma terapêutica não-medicamentosa, com probióticos e prebióticos associados, com a finalidade de restaurar o equilíbrio da flora intestinal e reduzir ou prevenir a inflamação. Sua ação inibiria a aderência de bactérias patogênicas às células do intestino, regularia melhor a permeabilidade da sua mucosa, diminuiria a translocação bacteriana e estimularia o aumento na síntese de $\lg A$ entérica (MISZPUTEN, 2015).

Uma terapêutica com probióticos que foi testada em pacientes com DII foi usando cepas bacterianas produtoras de butirato, uma vez que já se sabe que o butirato é um ácido graxo capaz de influenciar na saúde do intestino como um todo e na função da barreira epitelial e as cepas que o produzem estão em quantidade inferior em portadores de DC, se comparados com a quantidade presente em pessoas saudáveis. (GEIRNAERT et al., 2017) A redução da quantidade de Firmicutes, das famílias Ruminococcaceae e Lachnospiraceae, famílias que abrigam a maior parte das bactérias produtoras de butirato, é uma das principais características da disbiose na DII, principalmente na DC em atividade, o que pode explicar o distúrbio funcional da microbiota, como a redução da síntese de butirato. Na DC com comprometimento ileal identificaram a redução de F. prausnitzii e Roseburia sp.,

RC: 82101

Disponível em: https://www.nucleodoconhecimento.com.br/saude/modulacao-da- 
também produtores de butirato. (MATSUOKA; KANAI, 2015; MARCHESI JR et al., 2007; MORGAM et al., 2012) Eeckhaut et al. (2013), quantificaram Butyricicoccus, por PCR, nas fezes de portadores de DII e em pessoas saudáveis e verificaram que há uma variação na quantidade dessas bactérias, sendo menor sua representação na fase ativa que na fase de remissão da doença, a redução da quantidade é maior em portadores de DC que em portadores de CU e, em ambos os casos, bem menor que em pessoas saudáveis, correlacionando a concentração dessa bactéria a atividade da doença, além disso, a administração oral de B. pullicaecorum em ratos com colite induzida reduziu níveis de citocinas inflamatórias TNF-alfa, IL-12 e o sobrenadante de cultura de células com essas cepas impediu a perda da resistência transepitelial fortalecendo a barreira epitelial. Quévrain et al. (2016), em um estudo in vitro, identificou uma proteína com propriedades anti-inflamatórias produzida por F. prausnitzii, que foi capaz de inibir a via NF-kB em células intestinais e inibir colite em modelo animal. Geirnaert et al. (2017), compararam cultura de células Caco-2 e de amostras de fezes de cinco portadores de DC ativa e cinco de DC em remissão com isolado de F. prausnitzii, B. pullicaecorum 25-3 e B. pullicaecorum 1,20 e uma outra com um mix de seis cepas produtoras de butirato (B. pullicaecorum 25-3, $F$. prausnitzii, Roseburia hominis, Roseburia inulinivorans, Anaerostipes caccae e Eubacterium hallii). Houve um aumento 3\% maior na síntese de butirato e 2\% maior de acetato nas amostras de pacientes em remissão, e 6\% maior a síntese de propionato nas amostras de DC ativa, além disso, verificou-se uma tendência a reduzir níveis de butirato na $D C$ ativa; também se obteve uma redução significativa de Lachnospiraceae nas amostras de DC ativa. As amostras tratadas com $F$. prausnitzii e com o mix de bactérias apresentaram o maior aumento no volume de butirato produzido seguido de uma redução de acetato, provavelmente induzido pela alimentação metabólica cruzada de cepas produtoras de acetato e butirogênicas, tanto nas amostras de DC ativa quanto nas amostras quiescentes. Também houve aumento da colonização nas amostras tratadas com o mix, sendo a $E$. hallii a que melhor colonizou as amostras associadas ao muco e as de $F$. prausnitzii as que

RC: 82101

Disponível em: https://www.nucleodoconhecimento.com.br/saude/modulacao-da- 
colonizaram melhor o lúmen, e indicativos de boa formação de junções fortes e de uma função adequada da barreira intestinal.

Segundo a WGO (2017), os estudos de probióticos na DC indicaram que não há evidência de que os probióticos sejam benéficos para a manutenção da remissão na DC.

\subsubsection{MODULAÇÃO INTESTINAL COM PREBIÓTICOS}

Os prebióticos são capazes de estimular tanto o crescimento de um tipo específico de bactéria quanto influenciar em sua atividade. Dentre os mais estudados estão os frutanos inulina (inclusive frutoligossacarídeo (FOS) e galacto-oligossacarídeos (GOS), derivados de inulina) e oligofrutose. Esses frutanos são capazes de promover o aumento da quantidade de cepas produtoras de butirato, porém sua ingestão também está associada ao aumento de sintomas gastrointestinais, como dor abdominal, inchaço e diarreia. (ANDERSON et al., 2015; $\mathrm{KOH}$ et al., 2016) Anderson et al. (2015), em um estudo de caso-controle, analisou a composição da dieta de pacientes com DC ativa, inativa e em um grupo de pessoas saudáveis e identificou que portadores de DC consomem menos frutanos que pessoas saudáveis e portadores da doença ativa consomem menos que portadores da doença inativa. Wilson; Whelan (2017) fala que vários estudos demonstram benefícios da suplementação de inulina em humanos, aumentando 0 crescimento de bifidobactérias com baixas doses, se comparado com a dose recomendada de 20,9g a $87,3 \mathrm{~g}$ por dia para homens e $16,3 \mathrm{~g}$ a $65,3 \mathrm{~g}$ por dia para mulheres, apontada por Morrison e Preston (2016) em sua revisão sistemática, para se ter efeito modulador na microbiota, apontando uma modificação na microbiota suplementando $5 \mathrm{~g}$ a $8 \mathrm{~g}$ de inulina por duas vezes na semana e até $8 \mathrm{~g} / \mathrm{dia}$, e ressalta que esse efeito em dose baixa se aplica a microbiotas com população reduzida de bifdobactérias. Em humanos saudáveis, a Inulina atua como imunomodulador intestinal, aumentando IgA fecal, estimulando as Placas de Peyer a secretarem mais IL-10 e IFN-gama,

RC: 82101

Disponível em: https://www.nucleodoconhecimento.com.br/saude/modulacao-da- 
além de aumentar a atividade das células do sistema imune do baço. Outro estudo randomizado de controle cruzado, citado por Wilson e Whelan (2017), envolvendo suplementação de $7 \mathrm{~g}$ por dia de dois tipos de beta-GOS em 59 voluntários saudáveis, onde se pode verificar que ambos os tipos aumentaram a quantidade de bifidobactérias significativamente. Um ensaio cruzado de 10 semanas em 40 voluntários idosos, com suplementação de $5,5 \mathrm{~g}$ por dia, obteve resultado semelhante, além de ter aumentado IL-10, que é anti-inflamatória, e suprimido IL1 beta, que é inflamatória, sugerindo efeito imunomodulador. (WILSON; WHELAN, 2017) Sitkin; Vakhitov; Pokrotnieks (2018), após realizarem um estudo aberto randomizado com pacientes portadores de Colite Ulcerativa com suplementação de butirato de cálcio e inulina, concluíram que, apesar dos benefícios, a suplementação da fibra deve ser mais segura em pacientes com doença inativa devido a possibilidade de efeito colateral. Liu et al. (2017), realizaram um estudo autocontrolado, duplo cego, randomizado com suplementação de $16 \mathrm{mg}$ de FOS ou GOS (8g, duas vezes ao dia), em dois grupos de adultos saudáveis, de ambos os sexos, por 14 dias, e concluíram que apesar da suplementação promover um aumento de Bifidobacterium e reduzir a presença de bactérias patogênicas Enterobacter e Salmonella, devido ao aumento da produção de ácido lático, também reduziu a presença de bactérias produtoras de butirato, como Ruminococcus (no grupo de GOS) e Phascolarctobacterium (no grupo de FOS), reduzindo em $46,1 \%$ a presença de butirato nas fezes dos suplementados com FOS e uma tendência de redução de $31,2 \%$ no grupo suplementado com GOS. Além disso, na suplementação com GOS houve uma redução da diversidade bacteriana em comparação com a composição anterior a suplementação, enquanto na suplementação com FOS não houve interferência. Eles encontraram uma forte correlação entre a redução da quantidade de butirato e uma piora no metabolismo da glicose, sugerindo que a síntese de butirato influencia no desenvolvimento de resistência à insulina e DM2.

RC: 82101

Disponível em: https://www.nucleodoconhecimento.com.br/saude/modulacao-damicrobiota 


\section{CONSIDERAÇÕES FINAIS}

Diante de tudo o que foi exposto, concluo que há um processo multifatorial por trás da causa inicial da disbiose na ativação da Dll e que, em decorrência do próprio tratamento, esse estado disbiótico se mantém ou é agravado, gerando a necessidade de buscar alternativas de tratamento para reverter esse quadro.

A modulação da microbiota, seja através da dieta, ou por suplementação oral de butirato, pre e probióticos, pode ser uma alternativa adjuvante ao tratamento, mas que precisa ser mais estudado. A combinação desses fatores pode auxiliar no controle da doença e na reversão da disbiose, promovendo a homeostase intestinal e uma possível remissão sustentada. Estudos com probióticos apresentaram resultados promissores, reduzindo a inflamação e promovendo a cicatrização intestinal, mas nenhuma das pesquisas foi realizada com humanos, o que não garante que teremos os mesmos resultados em humanos. Os prebióticos influenciam na síntese de butirato e na quantidade de cepas butirogênicas e deve ser mais bem tolerado na fase de remissão, caso contrário poderá agravar os sintomas gastrointestinais. Os tipos de dieta já testados em portadores com DC aumentam a bisbiose da microbiota, e reduzem a inflamação, levando a indução da remissão por um caminho contrário do que se busca através da suplementação de pré e probióticos, que seria reduzir a disbiose para reduzir a inflamação. A suplementação de butirato pode ser uma opção de tratamento adjuvante no controle da inflamação intestinal e na regeneração da barreira epitelial em portadores de CU, mas não encontrei estudos em portadores de DC. Uma outra hipótese, que possa ser bem tolerada, e que não encontrei estudos testando sua eficácia, seria a suplementação de cisteína ou glutationa associado a riboflavina e inulina ou pectina, uma vez que a combinação desses suplementos pode promover o aumento da quantidade de $F$. prausnitzii, uma bactéria produtora de butirato e proteína com atividade anti-inflamatória.

RC: 82101

Disponível em: https://www.nucleodoconhecimento.com.br/saude/modulacao-damicrobiota 
Os estudos foram realizados com grupos pequenos de portadores de DII e por curto prazo, necessitando de mais estudos para entender melhor a resposta da doença diante das intervenções no médio e longo prazo. Há uma necessidade de continuidade para a manutenção da modulação, uma vez que em todos os estudos se observou um retorno ao estado inicial assim que a intervenção foi suspensa, configurando um caráter provisório à mudança.

\section{REFERÊNCIAS BIBLIOGRÁFICAS}

ALEKSANDROVA, Krasimira; ROMERO-MOSQUERA, Beatriz; HERNANDEZ, Vicent. Dieta, microbioma intestinal e epigenética: vínculos emergentes com doenças inflamatórias intestinais e perspectivas de tratamento e prevenção. Nutrients, [S. I.], v. 9, ed. 9, 30 ago. 2017. Disponível em: https://www.ncbi.nlm.nih.gov/pmc/articles/PMC5622722/. Acesso em: 13 maio 2020.

ANDERSON, Jacqueline L.; HEDIN, Charlotte R.; BENJAMIN, Jane L. et al. Ingestão dietética de frutanos do tipo inulina na doença de Crohn ativa e inativa e controles saudáveis: um estudo caso-controle. Journal of Crohn's and Colitis, [s. I.], ano 2015, v. 9, ed. 11, p. 1024-1031, novembro 2015. Disponível em: https://pubmed.ncbi.nlm.nih.gov/26221003/?from_term=crohn\%27s+disease+inulin\&f rom_pos=2. Acesso em: 29 abr. 2020.

ARPAIA, Nicholas et al. Metabólitos produzidos por bactérias comensais promovem geração periférica de células T reguladoras. Nature, [s. I.], v. 504, ed. 7480, p. 451455, 19 dez. 2013. Disponível em: https://www.ncbi.nlm.nih.gov/pmc/articles/PMC3869884/. Acesso em: 19 jun. 2020.

BONEH, Rotem Sigall; SHABAT, Chen Sarbagili; YANAI, Henit et al. A terapia dietética com a dieta de exclusão da doença de Crohn é uma estratégia bemsucedida para indução de remissão em crianças e adultos com falha na terapia biológica. Journal of Crohn's and Colitis, [s. I.], ano 2017, v. 11, ed. 10, p. 1205-

RC: 82101

Disponível em: https://www.nucleodoconhecimento.com.br/saude/modulacao-damicrobiota 
1212 ,

out.

2017.

Disponível

em:

https://pubmed.ncbi.nlm.nih.gov/28525622/?from_term=crohn\%27s+disease+diet\&fr om_pos=7. Acesso em: 3 maio 2020.

CAMPOS, Fábio Guilherme M. C. de; KOTZE, Paulo Gustavo. Burril Bernard Crohn (1884 - 1983): o homem por trás da doença. ABCD. Arquivos Brasileiros de Cirurgia Digestiva, São Paulo, Brasil, Dezembro 2013. Disponível em: http://www.scielo.br/scielo.php?script=sci_arttext\&pid=S0102-67202013000400001. Acesso em: 23 abr. 2019.

CANÁRIO, Helena. Microbiota e cultura de arranque. Nascer e crescer, Portugal, v. 21, n. 3, Setembro 2012. Disponível em: http://www.scielo.mec.pt/scielo.php?script=sci_arttext\&pid=S087207542012000300015. Acesso em: 25 abr. 2019.

CASTRO, Marina Moreira de; CORONA, Ligia Pires; PASCOAL, Lívia Bitencourt et al. Padrões alimentares associados a aspectos clínicos em pacientes com doença de Crohn. Scientific Reports, [s. I.], ano 2020, v. 10, ed. 1, 27 abr. 2020. Disponível em: https://pubmed.ncbi.nlm.nih.gov/32341416/. Acesso em: 9 maio 2020.

COX, Selina R.; LINDSAY, James O.; FROMENTIN, Sébastien et al. Efeitos da dieta baixa em FODMAP sobre sintomas, microbioma fecal e marcadores de inflamação em pacientes com doença inflamatória intestinal quiescente em um estudo randomizado. Gastroenterology, [s. I.], ano 2020, v. 158, n. 7, ed. 1, p. 176-188, janeiro 2020. Disponível em: https://www.gastrojournal.org/article/S0016$5085(19) 41366-$

8/fulltext?referrer=https\%3A\%2F\%2Fwww.nature.com\%2Farticles\%2Fs41598-02064024-1. Acesso em: 9 maio 2020.

EECKHAUT, Vanessa; MACHIELS, Kathleen; PERRIER, Clémentine et al. Butyricicoccus pullicaecorum na doença inflamatória intestinal. Gut, [s. I.], ano 2013,

RC: 82101

Disponível em: https://www.nucleodoconhecimento.com.br/saude/modulacao-damicrobiota 
v. 62 , ed. 12, p. 1745-1752, Dezembro 2013. Disponível em: https://www.ncbi.nlm.nih.gov/pubmed/23263527/. Acesso em: 16 maio 2020.

FARIAS, Carolina Lane Alves; THIEME, Rubia Daniela; HEYDE, Raul Von der. Vitamina B2: Riboflavina. In: SCHIEFERDECKER, Maria Eliana Madalozzo; THIEME, Rubia Daniela. Vitaminas, minerais e eletrólitos: Aspectos fisiológicos, nutricionais e dietéticos. 1. ed. Rio de Janeiro, Brasil: Rúbio, 2016. cap. 3, p. 41-51.

GASTROSITE. Doença de Crohn. [S. I.], [S.I.]. Disponível em: http://www.gastrosite.com.br/s_intestinofino.php. Acesso em: 26 maio 2020.

GEIRNAERT, Annelies; CALATAYUD, Marta; GROOTAERT, Charlotte et al. Bactérias produtoras de butirato suplementadas in vitro para pacientes com doença de Crohn Microbiota Aumento da produção de butirato e melhora da integridade da barreira epitelial intestinal. Scientific Reports: Nature Research, [s. I.], ano 2017, v. 7, ed. 1,13 set. 2017. Disponível em: https://pubmed.ncbi.nlm.nih.gov/28904372/?from_term=probi\%C3\%B3tic+crohn\%27 s+disease\&from_filter=simsearch2.ffrft\&from_filter=ds1.y_10\&from_pos=6. Acesso em: 16 maio 2020.

GERASIMIDIS, Konstantinos; BERTZ, Martin; HANSKE, Laura et al. Declínio nas espécies bacterianas e metabolitos presumivelmente protetoras está paradoxalmente associado à melhora da doença na doença de Crohn pediátrica durante a nutrição enteral. Inflamatory Bowel Diseases, [S. I.], ano 2014, v. 20, ed. 5, p. 861-871, maio 2014 Disponível em: https://pubmed.ncbi.nlm.nih.gov/24651582/. Acesso em: 13 maio 2020.

HALFELD, Laura Cotta Ornellas. Epidemiologia das Doenças Inflamatórias Intestinais. In: CURY, Dídia Bismara; MOSS, Alan Colm (org.). Doenças Inflamatórias Intestinais: Doença de Crohn e retocolite ulcerativa. 2. ed. Rio de Janeiro, Brasil: Rubio, 2015. cap. 1, p. 3.

RC: 82101

Disponível em: https://www.nucleodoconhecimento.com.br/saude/modulacao-damicrobiota 
HARTH-CHÚ, Erika Nikitza Shiauha et al. Microbiologia da cárie dentária. In: SPOLIDORIO, Denise M. Palomari; DUQUE, Cristiane. Microbiologia e imunologia geral e odontológica. São Paulo, Brasil: Artes Médicas, 2013. v. 1, cap. 6, p. 81.

ILIEV, I D; MILETI, E; MATTEOLI, G et al. As células epiteliais intestinais promovem a diferenciação reguladora das células $T$ reguladoras de proteção contra colite através do condicionamento das células dendríticas. Mucosa Immunology, [s. I.], ano 2009, p. 340-350, 22 abr. 2009. Disponível em: https://www.nature.com/articles/mi200913. Acesso em: 19 jun. 2020.

KEELER, Joann Romano; WEITKAMP, Jörn-Hendrik. Influências maternas na colonização microbiana fetal e no desenvolvimento imunológico. Pediatric Research, [s. I.], ano 2015, v. 77, p. 189-195, janeiro 2015. Disponível em: https://www.ncbi.nlm.nih.gov/pmc/articles/PMC4289016/. Acesso em: 23 abr. 2020.

KHAN, M Tanweer; DUNCAN, Sylvia H.; STAMS, Alfons J. M. et al. O Anaerobe Faecalibacterium Prausnitzii do intestino usa um transporte extracelular de elétrons para crescer em interfases oxico-anóxicas. The ISME Journal: Multidisciplinary Journal of Microbial Ecology, [s. I.], ano 2012, v. 6, ed. 8, p. 1578-1585, agosto 2012. Disponível em: https://www.ncbi.nlm.nih.gov/pmc/articles/PMC3400418/. Acesso em: 29 abr. 2020.

$\mathrm{KOH}$, Ara; VADDER, Filipe De; DATCHARY, Petia Kovatcheva; BÄCKHED, Fredrik. Da fibra alimentar à fisiologia do hospedeiro: Ácidos graxos de cadeia curta como principais metabólitos bacterianos. Cell, [s. I.], ano 2016, v. 165, ed. 6, p. 1332-1345, 2 jun. 2016. Disponível em: https://www.cell.com/cell/fulltext/S0092-8674(16)30592X?_returnURL=https\%3A\%2F\%2Flinkinghub.elsevier.com\%2Fretrieve\%2Fpii\%2FS0 09286741630592X\%3Fshowall\%3Dtrue. Acesso em: 26 abr. 2020.

KORELITZ, Dr. Burton I. Conheça a história da Doença de Crohn. ABCD em foco, São Paulo, Brasil, 19 fev. 2014. Disponível em:

RC: 82101

Disponível em: https://www.nucleodoconhecimento.com.br/saude/modulacao-damicrobiota 
https://abcd.org.br/blog/artigos/conheca-a-historia-da-doenca-de-crohn/. Acesso em: 23 abr. 2019.

LAGE, Olga. Microbiota do corpo humano. [S. I.], [2013?]. Disponível em: http://files.cienciapatodos.webnode.pt/200000025-

e6bd6e7b75/microbiota\%20do\%20corpo\%20humano_Olga\%20Lage.jpg. Acesso em: 26 maio 2020.

LASERNA-MENDIETA, Emilio J.; CLOONEY, Adam G.; CARRETERO-GOMEz, Julián F. et al. Determinantes da capacidade genética reduzida para a síntese de butirato pelo microbioma intestinal na doença de Crohn e na colite ulcerosa. Journal of Crohn's and Colitis, [s. I.], ano 2018, v. 12, ed. 2, p. 204-216, 24 jan. 2018. Disponível em: https://pubmed.ncbi.nlm.nih.gov/29373727/. Acesso em: 30 abr. 2020.

LIU, Feitong; LI, Pan; CHEN, Muxuan et al. Frutooligossacarídeo (FOS) e Galactooligosaccharide (GOS) aumentam a bifidobactéria, mas reduzem as bactérias produtoras de butirato com metabolismo glicêmico adverso em população jovem e saudável. Scientific Reports: Nature Research, [s. I.], ano 2017, v. 7, ed. 1, 18 set. 2017.

Disponível

em:

https://www.ncbi.nlm.nih.gov/pmc/articles/PMC5603605/. Acesso em: 6 maio 2020.

LOUIS, Petra; FLINT, Harry J. Formação de propionato e butirato pela microbiota colônica humana. Environmental Microbiology, [s. I.], ano 2017, v. 19, n. 1, p. 2941 , janeiro 2017.

Disponível

em: https://pubmed.ncbi.nlm.nih.gov/27928878/?from_term=microbiota+butyrate+synthes is\&from_pos=2. Acesso em: 23 abr. 2020.

MACHADO, Alessandra Barbosa Ferreira; OLIVEIRA, Marcelo Nagem Valério de; CARMO, Ana Paula do. Como estudar a microbiota gastrintestinal humana. In: MACHADO, Alessandra Barbosa Ferreira et al (org.). Microbiota gastrintestinal:

RC: 82101

Disponível em: https://www.nucleodoconhecimento.com.br/saude/modulacao-damicrobiota 
Evidências de sua influência na saúde e na doença. Rio de Janeiro, Brasil: Rúbio, 2015. cap. 2, p. 16.

MACLELLAN, Amber; MOORE-CONNORS, Jessica; GRANT, Shannan et al. O impacto da nutrição enteral exclusiva (EEN) no microbioma intestinal na doença de Crohn: uma revisão. Nutrients, [S. I.], ano 2017, v. 9, ed. 5, 1 maio 2017. Disponível em: https://pubmed.ncbi.nlm.nih.gov/28468301/. Acesso em: 13 maio 2020.

MARCHESI, J. R.; HOLMES, Elaine; KHAN, Fatima et al. Caracterização metabólica rápida e não invasiva da doença inflamatória intestinal. Journal of Proteome Research, [s. l.], ano 2007, v. 6, ed. 2, p. 546-551, fevereiro 2007. Disponível em: https://www.ncbi.nlm.nih.gov/pubmed/17269711. Acesso em: 16 maio 2020.

MATSUOKA, K; KANAI, T. A microbiota intestinal e a doença inflamatória intestinal. Seminars in Immunopathology, [s. I.], ano 2015, v. 37, ed. 1, p. 47-55, janeiro 2015. Disponível em: https://www.ncbi.nlm.nih.gov/pubmed/25420450/. Acesso em: 16 maio 2020.

MELO, Karina Mescouto; CARVALHO, Beatriz Tavares Costa. Células T regulatórias: mecanismos de ação e função nas doenças humanas. Revista Brasileira Alergia e Imunopatologia, [s. I.], ano 2009, v. 32, ed. 5, p. 184-188, 2009.

MEURER, Mariane Caroline. ATIVIDADE ANTI-INFLAMATÓRIA INTESTINAL DO EXTRATO SECO DE TageteserectaL.EM MODELO DE COLITE ULCERATIVA INDUZIDA POR DEXTRAN SULFATO DE SÓDIO (DSS)EM CAMUNDONGOS. Universidade do Vale do Itajaí: Programa de Pós-graduação em Ciências Farmacêuticas, Itajaí, SC, ano 2018, Julho 2018. Disponível em: https://docplayer.com.br/174637455-Mariane-caroline-meurer.html. Acesso em: 19 jun. 2020.

RC: 82101

Disponível em: https://www.nucleodoconhecimento.com.br/saude/modulacao-da$\underline{\text { microbiota }}$ 
MINISTÉRIO DA SAÚDE (Brasil). Secretaria de Atenção à Saúde. PORTARIA № 966, de 2 de outubro de 2014. Protocolo Clínico e Diretrizes Terapêuticas da Doença de Crohn, Brasil, 2 out. 2014. Disponível em: http://portalarquivos2.saude.gov.br/images/pdf/2014/outubro/07/pcdt-Dca-Crohn.pdf. Acesso em: 24 abr. 2019.

MISZPUTEN, Sender Jankiel; CURY, Dídia Bismara. Manifestações clínicas da Doença de Crohn. In: CURY, Dídia Bismara; MOSS, Alan Colm (org.). Doenças Inflamatórias Intestinais: Retocolite Ulcerativa e Doença de Crohn. 2. ed. Rio de Janeiro, Brasil: Rúbio, 2015. cap. 3, p. 24.

MISZPUTEN, Sender Jankiel. Terapêutica não biológica nas doenças inflamatórias intestinais. In: CURY, Dídia Bismara; MOSS, Alan Colm (org.). Doenças Inflamatórias Intestinais: Retocolite Ulcerativa e Doença de Crohn. 2. ed. Rio de Janeiro, Brasil: Rúbio, 2015. cap. 11, p. 111 - 120.

MOREIRA, Ana Paula Boroni; BARRA, Ângela Aparecida. Papel da microbiota na fisiologia do hospedeiro. In: MACHADO, Alessandra Barbosa Ferreira et al (org.). Microbiota gastrintestinal: Evidências de sua influência na saúde e na doença. Rio de Janeiro, Brasil: Rúbio, 2015. cap. 6.

MORGAN, X. C.; TIMOTHY, L. T.; SOKOL, H. et al. Disfunção do microbioma intestinal na doença inflamatória intestinal e tratamento. Genome Biol., [s. I.], ano 2012, v. 13, ed. 9, 16 abr. 2012. Disponível em: https://www.ncbi.nlm.nih.gov/pubmed/23013615. Acesso em: 16 maio 2020.

MORRISON, Douglas J.; PRESTON, Tom. Formação de ácidos graxos de cadeia curta pela microbiota intestinal e seu impacto no metabolismo humano. Gut Microbes, [s. I.], ano 2016, v. 7, ed. 3, p. 189-200, 2016. Disponível em: https://www.tandfonline.com/doi/full/10.1080/19490976.2015.1134082. Acesso em: 26 abr. 2020.

RC: 82101

Disponível em: https://www.nucleodoconhecimento.com.br/saude/modulacao-damicrobiota 
ORIÁ, Reinaldo B. Bases do Sistema Imunológico Associado à Mucosa Intestinal: Figura 15. Researchgate, [s. I.], 2016. Disponível em: https://www.researchgate.net/figure/Figura-152-Esquema-da-regiao-do-ileomostrando-um-arranjo-nodular-da-placa-de-Peyer_fig2_310792372. Acesso em: 19 jun. 2020.

PAIVA, Aline Dias; MANTOVANI, Hilário Cuquetto. Produtos da atividade metabólica da microbiota intestinal e suas implicações no metabolismo humano. In: MACHADO, Alessandra Barbosa Ferreira et al (org.). Microbiota gastrintestinal: Evidências de sua influência na saúde e na doença. Rio de Janeiro, Brasil: Rúbio, 2015. cap. 4, p. 50.

PELÁEZ, Carmen; REQUENA, Teresa. A microbiota intestinal humana. In: PELÁEZ, Carmen; REQUENA, Teresa. $O$ que sabemos da microbiota intestinal?. Madri, Espanha: Catarata, 2017. cap. 2.

PEREZ, Pablo F. et al. Impressão bacteriana do sistema imunológico neonatal: lições das células maternas?. Pediatrics: Official Journal of The American Academy of Pediatrics, [s. I.], ano 2007, v. 119, ed. 3, p. 724-732, março 2007. Disponível em: https://pediatrics.aappublications.org/content/119/3/e724.long. Acesso em: 26 maio 2020.

QIANG, Y et al. Butirato e ácido retinóico imprimem o desenvolvimento de células dendríticas tipo mucosa sinergicamente a partir de células da medula óssea. Clinical \& Experimental Immunology: The Journal of Translational Immunology, [s. I.], ano 2017, v. 189, ed. 3, p. 290-297, setembro 2017. Disponível em: $\quad$ https://www.ncbi.nlm.nih.gov/pmc/articles/PMC5543492/\#cei12990-bib-0023. Acesso em: 19 jun. 2020.

QUÉVRAIN, E.; MAUBERT, M. A.; MICHON, C. et al. Identificação de uma proteína anti-inflamatória de Faecalibacterium prausnitzii, uma bactéria comensal deficiente

RC: 82101

Disponível em: https://www.nucleodoconhecimento.com.br/saude/modulacao-da$\underline{\text { microbiota }}$ 
na doença de Crohn. Gut, [s. I.], ano 2016, v. 65, ed. 3, p. 415-425, março 2016. Disponível em: https://www.ncbi.nlm.nih.gov/pubmed/26045134/. Acesso em: 18 maio 2020.

QUINCE, C.; IJAZ, U. Z.; LOMAN, N. et al. Modulação extensiva do metagenoma fecal em crianças com doença de Crohn durante nutrição enteral exclusiva. American Journal Gastroenterology, [s. I.], ano 2015, v. 110, ed. 12, p. 1718-1729, $\quad$ Dezembro 2015.2 Disponível em: https://www.ncbi.nlm.nih.gov/pmc/articles/PMC4697132/. Acesso em: 15 maio 2020.

REIS, Nelzir Trindade. Interações provocadas por fármacos mais utilizados no tratamento de diversas patologias: Agentes que atuam sobre a dor, termorregulação, a inflamação e as viroses. In: REIS, Nelzir Trindade. Nutrição clínica: Interações fármaco $\mathrm{x}$ fármaco, fármaco $\mathrm{x}$ nutriente, nutriente $\mathrm{x}$ nutriente e fitoterápico $\mathrm{x}$ fármaco. Rio de Janeiro, Brasil: Rúbio, 2004. cap. 4, p. 126 - 127, 137 - 138 e 161.

SAKAMOTO, Naomasa; KONO, Suminori; WAKAI, Kenji et al. Fatores de risco dietético para doença inflamatória intestinal: um estudo multicêntrico de controle de casos no Japão. Inflamatory Bowel Diseases, [s. I.], ano 2005, v. 11, ed. 2, p. 154163 , fevereiro 2005.

Disponível

em: https://pubmed.ncbi.nlm.nih.gov/15677909/?dopt=Abstract. Acesso em: 9 maio 2020.

SILVA, Carlos Felipe Bernardes; LAUDANNA, Antônio Atílio. Doença inflamatória intestinal: Doença de Crohn e retocolite ulcerativa inespecífica. In: LOPES, Antonio Carlos et al (ed.). Diagnóstico e Tratamento: Gastroenterologia. 1. ed. Barueri, São Paulo: Manole, 2007. v. 3, cap. 9, p. 75 - 80.

SITKIN, Stanislav; VAKHITOV, Timur; POKROTNIEKS , Juris. Como aumentar a capacidade de produção de butirato do microbioma intestinal: os pacientes com DII realmente precisam de reposição de butirato e terapia butirogênica?. Journal of Crohn's and Colitis, [s. I.], ano 2018, v. 12, ed. 7, p. 881-882, julho 2018.

RC: 82101

Disponível em: https://www.nucleodoconhecimento.com.br/saude/modulacao-damicrobiota 
Disponível

em:

https://pubmed.ncbi.nlm.nih.gov/29528388/?from_term=crohn\%27s+disease+inulin\&f rom_pos=4. Acesso em: 30 abr. 2020.

SOUZA, Heitor S. Pereira de. Etiologia e patogênese das doenças inflamatórias intestinais: Conceitos atuais. In: CURY, Dídia Bismara; MOSS, Alan Colm (org.). Doenças Inflamatórias Intestinais: Retocolite Ulcerativa e Doença de Crohn. 2. ed. Rio de Janeiro, Brasil: Rúbio, 2015. cap. 2.

STAGG, Andrew J. Células dendríticas intestinais na saúde e na inflamação intestinal. Front Immunology, [s. I.], ano 2018, ed. 9, 6 dez. 2018. Disponível em: https://www.ncbi.nlm.nih.gov/pmc/articles/PMC6291504/. Acesso em: 19 jun. 2020.

SVOLOS, Vaios; HANSEN, Richard; NICHOLS, Ben et al. Tratamento da doença de Crohn ativa com uma dieta alimentar comum que replica a nutrição enteral exclusiva. Gastroenterology, [s. I.], ano 2019, v. 156, ed. 5, p. 1354-1367, abril 2019.

Disponível

em:

https://pubmed.ncbi.nlm.nih.gov/30550821/?from_term=exclusive+enteral+nutrition+ gut+microbiota+crohn\%27s+disease\&from_filter=simsearch2.ffrft\&from_filter=ds1.y_ 10\&from_pos=2. Acesso em: 15 maio 2020.

VALENTE, Flávia Xavier; CAMPOS, Tatiana do Nascimento; MORAES, Luís Fernando de Sousa. Microbiota e doenças intestinais. In: MACHADO, Alessandra Barbosa Ferreira et al. Microbiota Gastrintestinal: Evidências de sua influência na saúde e na doença. Rio de Janeiro, Brasil: Rúbio, 2015. Cap. 10, p. 132.

VAN IMMERSEEL, F; DUCATELLE, R.; DE VOS, M. et al. Bactérias anaeróbicas produtoras de ácido butírico como uma nova abordagem de tratamento probiótico para a doença inflamatória intestinal. Journal of Medical Microbiology, [s. I.], ano 2010, v. 59, ed. 2, p. 141-143, fevereiro 2010. Disponível em: https://www.ncbi.nlm.nih.gov/pubmed/19942690/. Acesso em: 16 maio 2020.

RC: 82101

Disponível em: https://www.nucleodoconhecimento.com.br/saude/modulacao-damicrobiota 
WALTON, C.; MONTOYA, M. P. B.; FOWLER, D.P. et al. A alimentação enteral reduz a atividade metabólica do microbioma intestinal na doença de Crohn: um estudo observacional. European Journal of Clinical Nutrition, [S. I.], ano 2016, v. 70, ed. 9, p. 1052-1056, 11 maio 2016. Disponível em: https://www.nature.com/articles/ejcn201674. Acesso em: 13 maio 2020.

WILSON, Bridgette; WHELAN, Kevin. Frutanos e galacto-oligossacarídeos prébióticos do tipo inulina: definição, especificidade, função e aplicação em distúrbios gastrointestinais. Journal of Gastroenterology Hepatology, [s. I.], ano 2017, v. 32 , ed. 1 p. 64-68, março 2017. Disponível em: https://pubmed.ncbi.nlm.nih.gov/28244671/?from_term=crohn\%27s+disease+inulin\&f rom_pos=3. Acesso em: 29 abr. 2020.

YAN, Peng-Guang; LI , Jing-Nan. Avanços no entendimento do microambiente intestinal e doença inflamatória intestinal: uma revisão. Chinese Medical Journal, [S. I.], ano 2017, v. 133, ed. 7, p. 834-841, 5 abr. 2020. Disponível em: https://www.ncbi.nlm.nih.gov/pmc/articles/PMC7147659/. Acesso em: 13 maio 2020.

ZALTMAN, Cyrla; MORAES, Antonio Carlos de; NEBEL, João. Marcadores inflamatórios nas doenças inflamatórias intestinais. In: CURY, Dídia Bismara; MOSS, Alan Colm (org.). Doenças Inflamatórias Intestinais: Retocolite Ulcerativa e Doença de Crohn. 2. ed. Rio de Janeiro, Brasil: Rúbio, 2015. cap. 9, p. 88.

ZHOU, Lei; CHU, Coco; TENG, Fei et al. As células linfóides inatas suportam células T reguladoras no intestino através da interleucina-2. Nature, [s. I.], ano 2019, p. 405409, abril 2019. Disponível em: https://pubmed.ncbi.nlm.nih.gov/30944470/. Acesso em: 21 jun. 2020.

Enviado: Fevereiro de 2020.

Aprovado: Abril de 2021.

RC: 82101

Disponível em: https://www.nucleodoconhecimento.com.br/saude/modulacao-damicrobiota 